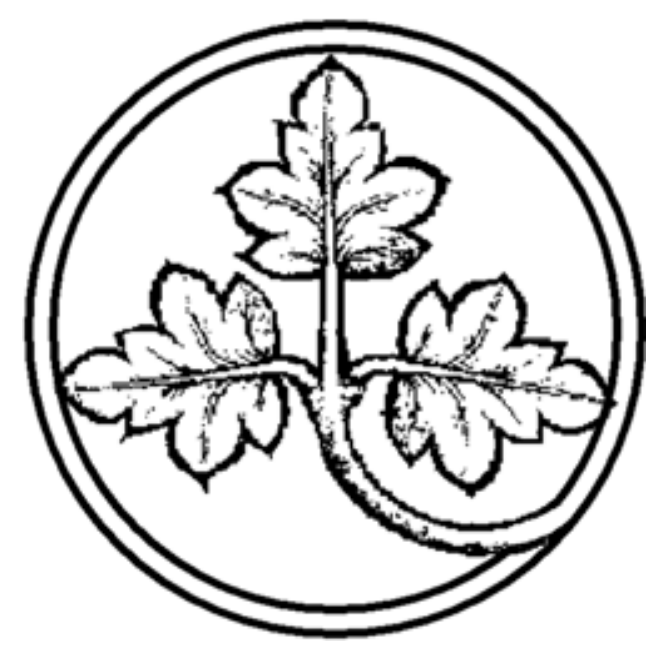

\author{
Preprints of the \\ Max Planck Institute \\ for Research on Collective Goods \\ Bonn \\ 2004/8
}

Nonlinear Incentive Provision in Walrasian Markets:

A Cournot Convergence Approach

Martin F. Hellwig 


\title{
Nonlinear Incentive Provision in Walrasian Markets: A Cournot Convergence Approach
}

\author{
Martin F. Hellwig
}

August 2004 


\title{
Nonlinear Incentive Provision in Walrasian Markets: A Cournot Convergence Approach*
}

\author{
Martin F. Hellwig \\ Max Planck Institute for Research on Collective Goods \\ Kurt-Schumacher-Str. 10 \\ D - 53113 Bonn, Germany, and \\ Sonderforschungsbereich 504 \\ University of Mannheim \\ D - 68163 Mannheim, Germany \\ hellwig@mpp-rgd.mpg.de
}

August 10, 2004

\begin{abstract}
The paper studies insurance with moral hazard in a system of contingent-claims markets. Insurance buyers are modelled as Cournot monopolists or oligopolists. The other agents condition their expectations on market prices, as in models of rational-expectations equilibrium with asymmetric information. Thereby they correctly anticipate accident probabilities corresponding to effort incentives induced by insurance buyers' net trades. When there are many agents to share the insurance buyer's risk, Cournot equilibrium outcomes are close to being second-best. In contrast, if insurance buyers are price takers, equilibria fail to exist or are bounded away from being second-best. Journal of Economic Literature Classification Numbers: D50, D62, D80.

Key Words: Insurance, Moral Hazard, Incentive Contracting, Walrasian Markets, Rational-Expectations, Cournot Equilibrium
\end{abstract}

${ }^{*}$ Final revision of Discussion Paper 00-42, Sonderforschungsbereich 504, University of Mannheim, forthcoming in Journal of Economic Theory. I am grateful for discussions with Richard Arnott, Tilman Börgers, Winand Emons, Piero Gottardi, Laurenz Kohlleppel, Joe Stiglitz, Thomas von Ungern-Sternberg, and especially Douglas Gale. I am also grateful for very helpful comments from two anonymous referees and an Associate Editor. Finally I thank the Deutsche Forschungsgemeinschaft for research support provided through the Sonderforschungsbereich 504 at the University of Mannheim. 


\section{Introduction}

Nonlinear incentive provision in Walrasian markets? Surely, the author doesn't know what he is talking about! Don't we all know that Walrasian markets involve linear price functionals, and that models involving Walrasian markets are therefore ill suited to the analysis of incentive contracting? Isn't this precisely why over the past two decades Walrasian general-equilibrium theory has had to make room for contract theory and game theory?

This stereotype view of the insignificance of Walrasian general-equilibrium theory for the analysis of incentive problems is flawed. In this paper, I develop a Walrasian-market model of insurance subject to moral hazard, which generates outcomes close to the outcomes of second-best incentive contracting. The model also provides a solution to the problem of exclusivity in contracting, which as yet is unsolved in contract theory.

In contract theory, incentive contracting is usually studied for a well specified set of agents without any explicit consideration of other agents in the economy. Relations of the contracting parties to other agents are subsumed in participation constraints reflecting opportunities from potential other matches. The possibility that the scope for incentive contracting itself may depend on the parties' relations with other agents in the economy is neglected.

If all contracts are publicly observable, this neglect does not matter: In this case, if multiple contracts are concluded, all participants are informed and are able to adjust their terms accordingly. For example, insurers providing a contract with a deductible know whether an insurance buyer concludes a second contract to cover the risk associated with the deductible and adjust their term to take account of the incentive implications of this second contract. Apart from the fact that more parties may be sharing the insurance buyer's risk, the overall outcome then is the same as in contracting with a single insurer.

However, if not all contracts are publicly observable, the ability to contract with an additional insurer undermines the viability of an arrangement with a deductible. If a contract with one insurer involves a deductible, the insurance buyer has an incentive to conclude a second contract with another insurer to cover the risk associated with the deductible. The second insurer would know that his client has poor incentives to take care and would price this contract accordingly. The risk averse insurance buyer would nevertheless be happy to deal with him in order to get rid of the risks that are left over under the first contract. The parties to the second contract neglect the externality they impose on the first insurer as the additional coverage 
reduces incentives to take care against accidents. If the first insurer is aware of the situation, he in turn will price his contract accordingly. The insurance buyer may then be worse off than he would be if he could commit to an exclusivity clause tying him to just one insurer $([21,38,16,5,6,7])$.

Most contract-theoretic analyses neglect this problem. Following Rothschild and Stiglitz [35], they assume that insurers are in a position to effectively impose exclusivity clauses that prohibit secret side-contracting. However, the enforcement of such clauses requires communication among the insurers. As shown by Jaynes [21] for the case of asymmetric information and by Hellwig [16] for the case of moral hazard, there is no reason to suppose that such inter-insurer communication will occur voluntarily as a feature of insurance market equilibrium.

The present paper shows that the exclusivity problem for incentive contracting disappears if one looks at the provision of insurance subject to moral hazard in the context of a Walrasian (Arrow-Debreu) system of organized markets for contingent claims. In this setting there is no room for the notion that an insurance buyer might obtain additional insurance through additional contracts. The overall insurance that he gets is determined by his trade with "the market". In a market equilibrium, this trade with "the market" is equal to the sum of trades with all other agents in the economy. Because all agents in the economy participate in the market, there is no scope for concluding additional contracts with additional agents.

Walrasian models of contingent-claims markets were considered early on in the literature on insurance with moral hazard, but were soon discarded because they seemed incompatible with efficient incentive provision. As argued by Pauly [31], equilibrium outcomes in such markets involve too much insurance and too little effort to prevent accidents. For example, if insurance sellers are close to being risk neutral, equilibrium prices must correspond to approximately fair odds, so the risk averse insurance buyer will demand close to full insurance, which leaves hardly any incentive to take effort against accidents. Relative to an efficient allocation that involves positive effort and partial insurance, there is too little effort and too much insurance. $^{1} 2$

\footnotetext{
${ }^{1}$ The argument presumes that an equilibrium exists. As shown in Proposition 6.1 below, an equilibrium fails to exist if at fair odds corresponding to zero effort, insurance is so expensive that the consumer prefers not to insure himself at all and to take care instead, see also $[19,2,38,17]$.

${ }^{2}$ The inefficiency is similar to the inefficiency that results from contracting without effective exclusivity clauses, see Bisin and Guaitoli [7]. Given the difficulties associated with linear budget constraints in the Walrasian tradition, Bisin and Gottardi $[5,6]$ as well as Bisin and Guaitoli [7] have introduced models based on "minimal" departures from
} 
Pauly's argument rests on the assumption that the insurance buyer is a price taker. This assumption is standard in the analysis of competitive Walrasian markets. Nevertheless, the assumption of price-taking behaviour is problematic because it is not based on a more fundamental analysis of strategic interactions based on the primitives of the model. This paper shows that this assumption is actually inappropriate for models of insurance subject to moral hazard. A proper treatment of strategic behaviour leads to a very different assessment of market outcomes.

Usually, the assumption of price-taking behaviour is justified as an approximation of behaviour in a large economy in which the individual agent is small relative to the market. In any finite economy, each agent actually has the power to affect market-clearing prices by changing the excess demand function that he transmits to the market, but this power is deemed to be small if the agent is small relative to the overall economy. The concept of Walrasian competitive equilibrium with price-taking behaviour by all agents is then seen as a useful approximation, which avoids the complexity of a precise strategic analysis while retaining the essence of the market allocation problem.

For markets without moral hazard or adverse selection, this view of price taking has, by and large, been supported by the literature on Cournot convergence $([9,29,14,15,39])$. For sequences of Walrasian market systems in which individual agents are becoming small relative to the overall economy, the equilibrium outcomes of Cournot models, in which agents appreciate the power they have over prices, will under certain regularity conditions converge to the equilibrium outcomes of the corresponding "competitive" models, in which agents are assumed to take prices as given.

However, for markets with moral hazard or asymmetric information, the view of price taking as a suitable approximation of behaviour in Walrasian markets is by and large incorrect. For markets with asymmetric information, this has been shown by Kyle [23] as well as Gale and Hellwig [10, 11]. For a market with moral hazard, this is shown in the present paper.

The paper studies Cournot convergence in a system of contingent-claims markets with moral hazard. In a model with a given finite number of partic-

such linear budget constraints.

A somewhat different literature on competitive markets under moral hazard or asymmetric information simply assumes exclusivity and identifies the commodity space with the space of "contracts", see [32, 22, 4, 24]. Mechanisms of price determination in this literature are actually closer to the Bertrand model that underlies the contract theoretic models than to the Walrasian model of pricing with a view to the law of demand and supply. 
ipants, an insurance buyer does not take prices as given, but takes account of the effects that his demands and supplies of contingent claims have on market prices. If there are many other agents to share risks, the equilibrium outcomes of this insurance market with moral hazard are shown to be close to the second-best outcomes that are predicted by contract theory when exclusivity clauses can be enforced. If these second-best outcomes involve positive effort and less than full insurance, the insurance buyer's behaviour is far from that of a price taker, no matter how small he may be in relation to the market as a whole.

The analysis rests on the following considerations:

- The issue of secrecy vs. transparency of the set of contracts concluded by the insurance buyer does not arise. The vector of excess demands for contingent claims which the insurance buyer transmits to "the market" reflects the total of his transactions with all other agents in the system. This total, which is all that matters for incentives, is reflected in market prices.

- By looking at market prices, the other traders in the economy can infer the insurance buyer's aggregate position and hence the incentives he has to take care against accidents. ${ }^{3}$ As in the literature on rationalexpectations equilibrium in markets with asymmetric information (see, e.g., Grossman [13]), the demand and supply functions that the other traders transmit to "the market" are chosen in such a way that for each price vector $\mathbf{q}$, demands and supplies at $\mathbf{q}$ incorporate the information about the insurance buyer's incentives that would be implied by $\mathbf{q}$ being the market-clearing price vector.

- The dependence of market-clearing prices on the insurance buyer's quantity choices contains an information effect. If the insurance buyer raises his demand for insurance and this information is transmitted to the other market participants through the associated change in prices, they will appreciate that, with more insurance, the insurance buyer has worse incentives and the accident probability is higher.

- The information effect in the dependence of market-clearing prices on the insurance buyer's quantity choices enhances the standard monopoly effect by which he restricts the quantities that he trades in order not to

\footnotetext{
${ }^{3}$ In the same vein, Admati et al. [1], fn. 14, p. 1107, argue that small shareholders of a firm can use the market price of the firm's shares to infer the stockholdings and hence the monitoring incentives of a large shareholder.
} 
spoil prices and to obtain a larger share of the surplus that is generated by his trading with the rest of the economy.

- When there are many agents to trade with and the insurance buyer is small relative to the market, the standard monopoly effect concerning the division of surplus between the insurance buyer and the insurers is negligible.

- In contrast to the standard monopoly effect, the information effect of the insurance buyer's quantity choices on prices does not disappear if the insurance buyer is small relative to the market. This information effect reflects only the insurance buyer's incentives at different quantity choices and has little to do with his size relative to the market. ${ }^{4}$ As the insurance buyer takes the information effect of his quantity choices on market prices into account, he never acts as if prices were even approximately independent of his quantity choices.

- As the insurance buyer takes the information effect of his quantity choices on market prices into account, he never acts as if prices were even approximately independent of his quantity choices. Regardless of how small he is relative to the market, the price-taking assumption fails to provide an even approximately appropriate description of his behaviour.

- However, as in models with perceived demand curves becoming infinitely elastic, the aggregate surplus available to other agents from providing insurance goes to zero. Because of this limiting "no surplus property", the insurance buyer ends up choosing socially optimal (second-best) net trades.

In the following, Section 2 lays out the simplest model of insurance subject to moral hazard. This model involves one potential insurance buyer and $H$ potential insurance sellers. For this model, Section 3 characterizes second-best allocations. Section 4 introduces the notion of a rational expectations offer curve as the key analytical tool for analysing the behaviour of insurance providers when market prices contain information about the insurance buyer's incentives. Section 5 defines and characterizes Walrasian (price-taking) and Cournot rational-expectations equilibria. Section 6 shows that Cournot rational expectations equilibrium allocations converge

\footnotetext{
${ }^{4}$ This has previously been observed by Marshall [28].
} 
to second-best outcomes when the number of insurance providers goes out of bounds. This section also shows that Walrasian rational-expectations equilibrium allocations converge to the full-insurance/zero-effort outcome or cease to exist. Section 7 extends the analysis to a specification with multiple insurance buyers acting as Cournot oligopolists, allowing for the number of insurance buyers as well as the number of insurers to become large. In Section 8, the paper concludes with a brief assessment of how contract-theory and Walrasian general-equilibrium theory handle the exclusivity problem associated with nonlinear incentive contracting. Proofs are given in the Appendix.

\section{The Basic Model}

I consider a general-equilibrium version of the standard model of insurance with moral hazard. There are two states of nature $s=1,2$, and, for each state of nature, one commodity. There are $H+1$ households $h=0,1, \ldots, H$, with initial endowments $e_{s}^{h}$ of the commodity in state $s$, for $s=1,2$. The endowment of household 0 depends on the state, namely,

$$
e_{1}^{0}=w^{0}>0, e_{2}^{0}=w^{0}-d>0,
$$

with the interpretation that $d>0$ represents material damage from an accident that happens to household 0 in state 2 . The endowments of households $1, \ldots, H$ do not depend on the state. For simplicity, these households are assumed to have the same characteristics, ${ }^{5}$ in particular the same endowments

$$
e_{s}^{h}=w^{1}>0
$$

for $s=1,2$ and $h=1, \ldots, H$. The endowment specification has been chosen so that in principle there should be scope for households $1,2, \ldots, H$, with their riskless endowments, to accept some of the endowment risk of household 0 , providing him with insurance through the exchange of contingent claims.

However there is moral hazard. The probabilities of states 1 and 2 depend on the effort that household 0 devotes to the avoidance of accidents. The household finds effort costly. His preferences over triples $\left(c_{1}^{0}, c_{2}^{0}, \eta\right)$

\footnotetext{
${ }^{5}$ When households $1,2, \ldots, H$ all have the same characteristics, one can talk about changes in the importance of household 0 relative to the market by simply changing the number $H$ of potential trading partners of household 0 . If these households differ, then for any sequence of economies with $H$ going out of bounds one has to specify the corresponding sequence of endowment and preference distributions along the lines of Hildenbrand [20]. This is easily done and leads to similar results as the replication approach used here.
} 
of state-contingent consumption plans and effort levels have the expectedutility representation

$$
U\left(c_{1}^{0}, c_{2}^{0}, \eta\right)=p_{1}(\eta) u\left(c_{1}^{0}\right)+p_{2}(\eta) u\left(c_{2}^{0}\right)-\eta,
$$

where, for $s=1,2, p_{s}(\eta)$ is the probability of state $s$ induced by the effort level $\eta$ and $u\left(c_{s}^{0}\right)-\eta$ is the von Neumann-Morgenstern utility that he associates with the consumption level $c_{s}^{0}$ and effort level $\eta$ in the state $s$.

Households $1,2, \ldots H$ have not only the same endowments, but also the same preferences over state-contingent consumption plans. Their preferences depend on the probabilities $p_{1}(\eta), p_{2}(\eta)$ of states 1 and 2 and hence, implicitly, on the effort of household 0 . For a given effort level $\eta$ of household 0 , the preferences of households $h=1,2, \ldots, H$ have the expected-utility representation

$$
V\left(c_{1}^{1}, c_{2}^{1}, \eta\right)=p_{1}(\eta) v\left(c_{1}^{h}\right)+p_{2}(\eta) v\left(c_{2}^{h}\right),
$$

where, for $s=1,2, v\left(c_{s}^{h}\right)$ is the von Neumann-Morgenstern utility that household $h$ associates with the consumption $c_{s}^{h}$ in state $s$.

The von Neumann-Morgenstern utility functions $u($.$) and v($.$) are as-$ sumed to be strictly increasing, and strictly concave on $\Re_{+}$, as well as twice continuously differentiable on $\Re_{++}$, with $\lim _{c \rightarrow 0} u^{\prime}(c)=\lim _{c \rightarrow 0} v^{\prime}(c)=\infty$. The probability functions $p_{1}($.$) and p_{2}($.$) are assumed to be twice contin-$ uously differentiable functions on $\Re_{+}$; moreover $p_{2}($.$) is strictly decreasing$ and strictly convex, with $p_{2}^{\prime \prime}(\eta)>0$ for all $\eta$, and $p_{1}()=.1-p_{2}($.$) is strictly$ increasing and strictly concave. To simplify the exposition, I also assume that $\lim _{\eta \rightarrow 0}\left|p_{2}^{\prime}(\eta)\right|=\infty$ so that the exertion of just a little effort reduces the accident probability by an amount that is large in relation to the effort that is exerted.

I assume that household 0 chooses the effort level $\eta$ after his consumption plan $\left(c_{1}^{0}, c_{2}^{0}\right)$ has been determined. Moreover I assume that his choice of $\eta$ is not observed by anybody else and therefore is not subject to any effective direct control. This implies that whatever effort level $\eta$ is actually implemented must satisfy the incentive compatibility condition

$$
\eta \in \arg \max _{\eta^{\prime}}\left[\left(1-p_{2}\left(\eta^{\prime}\right)\right) u\left(c_{1}^{0}\right)+p_{2}\left(\eta^{\prime}\right) u\left(c_{2}^{0}\right)-\eta^{\prime}\right],
$$

with $\left(c_{1}^{0}, c_{2}^{0}\right)$ taken as given.

The given assumptions on $p_{2}($.$) ensure that for any consumption plan$ $\left(c_{1}^{0}, c_{2}^{0}\right)$ of household 0 , the maximization problem in (2.3) is very well behaved. Formally one obtains: 
Lemma 2.1 For any consumption plan $\left(c_{1}^{0}, c_{2}^{0}\right) \in \Re_{+}^{2}$, the maximization problem in (2.3) has a unique solution $\eta\left(c_{1}^{0}, c_{2}^{0}\right) \geq 0$, so $\eta$ satisfies (2.3) for $\left(c_{1}^{0}, c_{2}^{0}\right)$ if and only if $\eta=\eta\left(c_{1}^{0}, c_{2}^{0}\right)$. The function $\eta(.,$.$) is continuous on$ $\Re_{+}^{2}$. If $c_{1}^{0} \leq c_{2}^{0}$, then $\eta\left(c_{1}^{0}, c_{2}^{0}\right)=0$. If $c_{1}^{0}>c_{2}^{0}$, then $\eta\left(c_{1}^{0}, c_{2}^{0}\right)>0$ and in a neighbourhood of $\left(c_{1}^{0}, c_{2}^{0}\right), \eta(.,$.$) is continuously differentiable with$

$$
\frac{\partial \eta}{\partial c_{1}^{0}}\left(c_{1}^{0}, c_{2}^{0}\right)=-\frac{p_{2}^{\prime}(\eta) u^{\prime}\left(c_{1}^{0}\right)}{p_{2}^{\prime \prime}(\eta)\left[u\left(c_{1}^{0}\right)-u\left(c_{2}^{0}\right)\right]}>0
$$

and

$$
\frac{\partial \eta}{\partial c_{2}^{0}}\left(c_{1}^{0}, c_{2}^{0}\right)=\frac{p_{2}^{\prime}(\eta) u^{\prime}\left(c_{2}^{0}\right)}{p_{2}^{\prime \prime}(\eta)\left[u\left(c_{1}^{0}\right)-u\left(c_{2}^{0}\right)\right]}<0
$$

Condition (2.3) and Lemma 2.1 indicate the usual tension between insurance and incentives. The less of a difference there is between the household's utility of consumption in the "normal" state and his utility of consumption in the accident state, the less inclined he is to take care against having an accident. This effect precludes the attainment of a first-best allocation, i.e., an allocation $\left(\left\{c_{1}^{h}, c_{2}^{h}\right\}_{h=0}^{H}, \eta\right)$ of state-contingent consumption plans and an effort level which is feasible as well as Pareto-efficient relative to the set of feasible allocations, i.e. the set of allocations satisfying

$$
\sum_{h=0}^{H} c_{s}^{h}=\sum_{h=0}^{H} e_{s}^{h}
$$

for $s=1,2$. If $H$ is large, first-best efficiency requires that households $1,2, \ldots, H$ take over close to all of household 0 's risk of damage in state 2. This implies that the difference between $u\left(c_{1}^{0}\right)$ and $u\left(c_{2}^{0}\right)$ is close to zero. With $\lim _{\eta \rightarrow 0}\left|p_{2}^{\prime}(\eta)\right|=\infty$, first-best efficiency also requires that the effort level $\eta$ be positive and bounded away from zero regardless of $H$. When taken together, these two implications of first-best efficiency are incompatible with incentive compatibility.

\section{Second-Best Allocations}

Given the need for incentive compatibility, the notion of second-best efficiency provides a suitable normative standard. An allocation $\left(\left\{c_{1}^{h}, c_{2}^{h}\right\}_{h=0}^{H}, \eta\right)$ of state-contingent consumption plans and an effort level is second-best if it is incentive-compatible and feasible as well as Pareto-efficient relative to the 
set of all incentive-compatible and feasible allocations. Second-best allocations are obtained as solutions to constrained maximization problems of the form

$$
\max _{\left(\left\{c_{1}^{h}, c_{2}^{h}\right\}_{h=0}^{H}, \eta\right)} U\left(c_{1}^{0}, c_{2}^{0}, \eta\right)
$$

subject to (2.3), (2.6), and

$$
V\left(c_{1}^{1}, c_{2}^{1}, \eta\right) \geq \bar{v}^{h} \text { for } h=1,2, \ldots, H,
$$

where $\bar{v}^{1}, \ldots, \bar{v}^{H}$ are parametrically given. If the utility bounds $\bar{v}^{h}$ are all the same, second-best allocations involve equal treatment of households $h=1,2, \ldots, H$. Adapting a result of Shavell [37], the following proposition provides a characterization of equal-treatment second-best allocations.

Proposition 3.1 Let $\left(\left\{c_{1}^{h}, c_{2}^{h}\right\}_{h=0}^{H}, \eta\right)$ be an equal-treatment second-best allocation with common utility bound $\bar{v}^{h}=\bar{v}$ for $h=1,2, \ldots, H$. Then

$$
\begin{gathered}
\eta>0 \\
w^{0}-d+H\left(w^{1}-v^{-1}(\bar{v})\right)<c_{2}^{0}<c_{1}^{0}<w^{0}+H\left(w^{1}-v^{-1}(\bar{v})\right), \\
c_{2}^{1}<v^{-1}(\bar{v})<c_{1}^{1}
\end{gathered}
$$

and

$$
\frac{u^{\prime}\left(c_{1}^{0}\right)}{u^{\prime}\left(c_{2}^{0}\right)}<\frac{v^{\prime}\left(c_{1}^{1}\right)}{v^{\prime}\left(c_{2}^{1}\right)}
$$

Condition (3.5) shows that in a second-best allocation, households $1,2, \ldots, H$ take over some of household 0's accident risk, i.e. the presence of moral hazard does not eliminate risk sharing altogether. However, second-best risk sharing is less than first-best risk sharing, which would be characterized by Borch's [8] condition

$$
\frac{u^{\prime}\left(c_{1}^{0}\right)}{u^{\prime}\left(c_{2}^{0}\right)}=\frac{v^{\prime}\left(c_{1}^{1}\right)}{v^{\prime}\left(c_{2}^{1}\right)}
$$

for equality of the different households' marginal rates of substitution. The discrepancy between the different households' marginal rates of substitution in (3.6) reflects the external effect on households $1, \ldots, h$ that arises as a reallocation household 0's consumption across states affects his effort incentives.

If the number $H$ of potential insurers of household 0 is large, there are many people to share his risk, so any one of them takes only a small share 
of it. Because expected-utility maximizers are approximately risk neutral towards small stakes, risk premia are then very small. This consideration yields:

Proposition 3.2 For $H=1,2, \ldots$, let $\left(\left\{c_{1}^{h H}, c_{2}^{h H}\right\}_{h=0}^{H}, \eta^{H}\right)$ be an equaltreatment second-best allocation with associated common utility bound $\bar{v}^{h H}=$ $v\left(w^{1}\right)$, regardless of $h$ and $H$. If $\left(c_{1}^{0}, c_{2}^{0}\right)$ is a limit point of the sequence $\left\{\left(c_{1}^{0 H}, c_{2}^{0 H}\right)\right\}_{H=1}^{\infty}$, then $\left(c_{1}^{0}, c_{2}^{0}\right)$, with associated effort level $\eta\left(c_{1}^{0}, c_{2}^{0}\right)$, solves the problem

$$
\max _{\left(c_{1}^{0}, c_{2}^{0}\right)} U\left(c_{1}^{0}, c_{2}^{0}, \eta\left(c_{1}^{0}, c_{2}^{0}\right)\right)
$$

subject to

$$
\left(1-p_{2}\left(\eta\left(c_{1}^{0}, c_{2}^{0}\right)\right)\right) c_{1}^{0}+p_{2}\left(\eta\left(c_{1}^{0}, c_{2}^{0}\right)\right) c_{2}^{0} \leq w^{0}-p_{2}\left(\eta\left(c_{1}^{0}, c_{2}^{0}\right)\right) d .
$$

Proposition 3.2 relates the model to the usual analysis of insurance with moral hazard when insurers are risk neutral. Maximization of $U\left(c_{1}^{0}, c_{2}^{0}, \eta\left(c_{1}^{0}, c_{2}^{0}\right)\right)$ subject to (3.9) is in fact the second-best problem as formulated, e.g., by Shavell [37] or, in a slightly different form, with effort costs measured in consumption rather than utility units, by Pauly [31]. As in models without moral hazard or asymmetric information (e.g., [3, 27]), the allocation of individual risks in a large economy with many risk averse insurers subdividing the risk poses approximately the same allocation problem as the allocation of the same risk in an economy with an arbitrary number of - sufficiently wealthy - risk neutral insurers.

\section{Rational-Expectations Offer Curves in Walrasian Markets}

In the remainder of the paper, I study what allocations are generated in competitive markets. Most of the literature looks at this question in terms of Bertrand competition among risk neutral insurers; an example is Shavell [37]. If insurers can enforce exclusivity, Bertrand competition induces efficient bilateral contracting and the insurers' problem in Bertrand competition can be identified with the welfare problem of maximizing (3.8) subject to (3.9). Market outcomes then are automatically second-best. However, there is no explanation of why exclusivity should be enforceable. If exclusivity is not enforceable, equilibrium outcomes are usually far from second-best $([2,38,16,17])$. 
As an alternative to the Bertrand approach, I study insurance provision in a complete system of organized markets for contingent claims à la ArrowDebreu. Here such a system involves claims on state 1 and claims on state 2 , with associated prices $q_{1}$ for a claim to one unit of the commodity in state 1 and $q_{2}$ for a claim to one unit of the commodity in state 2. At any price vector $\mathbf{q}=\left(q_{1}, q_{2}\right)$, households $h=0,1, \ldots, H$ announce excess demand vectors $\left(c_{1}^{h}(\mathbf{q})-e_{1}^{h}, c_{2}^{h}(\mathbf{q})-e_{2}^{h}\right)$; a Walrasian auctioneer chooses $\mathbf{q}$ so as to clear the markets (if such a $\mathbf{q}$ exists). Without loss of generality, the price vector $\mathbf{q}$ is assumed to be chosen from the nonnegative simplex

$$
\Sigma:=\left\{\left(q_{1}, q_{2}\right) \in \Re_{+}^{2} \mid q_{1}+q_{2}=1\right\} .
$$

When a market-clearing price vector has been found and the corresponding trades have been concluded, household 0 chooses his effort level $\eta$. His trading partners do not observe his choice and have no way to prevent him from choosing whatever effort level he wants to choose. However they are aware of the situation and try to anticipate his choice. They appreciate that if his trades in the market enable him to reach the consumption plan $\left(c_{1}^{0}, c_{2}^{0}\right)$, then he is likely to choose the effort level $\eta\left(c_{1}^{0}, c_{2}^{0}\right)$ which is optimal at this consumption plan. As a condition of equilibrium, they are required to have rational expectations about the effort choices of household 0.

I am not actually assuming that the other households observe the consumption plan of household 0 . They merely observe market prices and appreciate that there is a relation between the price vector which clears the market and the consumption plan of household 0. As they announce their own demands and supplies of contingent claims at any price vector $\mathbf{q}$, they ask themselves what effort level would be chosen by household 0 if the market actually cleared at this price vector. The idea is that different statecontingent consumption plans of household 0 , say $\left(c_{1}^{0}, c_{2}^{0}\right)$ and $\left(\hat{c}_{1}^{0}, \hat{c}_{2}^{0}\right)$, give rise to different market-clearing prices, $\mathbf{q}$ and $\hat{\mathbf{q}}$. From observing whether the price vector is $\mathbf{q}$ or $\hat{\mathbf{q}}$, households $1, \ldots, H$ can infer whether the household 0 's consumption is $\left(c_{1}^{0}, c_{2}^{0}\right)$ or $\left(\hat{c}_{1}^{0}, \hat{c}_{2}^{0}\right)$ and whether his effort level is $\eta\left(c_{1}^{0}, c_{2}^{0}\right)$ or $\eta\left(\hat{c}_{1}^{0}, \hat{c}_{2}^{0}\right)$.

The reader may wonder why this inference from prices to effort levels should work. Couldn't it be the case that some price vector $\mathbf{q}$ is generated as a market-clearing price vector by several consumption plans of household 0 ? In this case, the effort level of household 0 could not be inferred from the observation of $\mathbf{q}$ because the other households would not know which of the several consumption plans generating $\mathbf{q}$ the insurance buyer was actually pursuing. 
In principle this could be a serious problem. However, the following lemma shows that if households $1, \ldots, H$ are price takers, then the structure here is simple enough to provide for a one-to-one relation between marketclearing prices and state-contingent consumption plans of household 0 . The argument is similar to one given by Grossman [13] for a model with asymmetric information. I begin by observing that for any $\mathbf{q}=\left(q_{1}, q_{2}\right) \in \boldsymbol{\Sigma}$ and any $\eta \in \Re_{+}$, if $\mathbf{q}>>0$, the problem of maximizing $V\left(c_{1}^{1}, c_{2}^{2}, \eta\right)$ under the constraint $q_{1} c_{1}^{1}+q_{2} c_{2}^{2}=w^{1}$ has a unique solution $\left(c_{1}^{1}(\mathbf{q}, \eta), c_{2}^{1}(\mathbf{q}, \eta)\right)$. Moreover $c_{1}^{1}(\mathbf{q}, \eta)$ is nondecreasing and $c_{2}^{1}(\mathbf{q}, \eta)$ is nonincreasing in $\eta$. In combination with Lemma 2.1, this observation yields:

Lemma 4.1 For any $\mathbf{q}=\left(q_{1}, q_{2}\right) \in \boldsymbol{\Sigma}$ such that $\mathbf{q}>>0$, there exists at most one pair $\left(c_{1}^{0}, c_{2}^{0}\right) \in \Re_{+}^{2}$ such that

$$
c_{1}^{0}+H c_{1}^{1}\left(\mathbf{q}, \eta\left(c_{1}^{0}, c_{2}^{0}\right)\right)=w^{0}+H w^{1}
$$

and

$$
c_{2}^{0}+H c_{2}^{1}\left(\mathbf{q}, \eta\left(c_{1}^{0}, c_{2}^{0}\right)\right)=w^{0}-d+H w^{1} .
$$

If households $1, \ldots, H$ are price takers, then equations (4.2) and (4.3) are the conditions for market clearing when household 0 chooses the consumption plan $\left(c_{1}^{0}, c_{2}^{0}\right)$ and households $1, \ldots, H$ correctly anticipate that he will choose the effort level $\eta\left(c_{1}^{0}, c_{2}^{0}\right)$. The lemma shows that for any strictly positive price vector $\mathbf{q} \in \Sigma$ there is no more than one consumption plan for which q clears the market if households $1, \ldots, H$ correctly anticipate the associated effort level chosen by household 0 . This permits an unambiguous inference from the price vector $\mathbf{q}$ that is observed in the market to the effort level $\eta^{*}(\mathbf{q})$ that is to be anticipated if $\mathbf{q}$ clears the market.

To develop this point formally, let $Q \subset \Sigma$ be the set of price vectors $\mathbf{q}>>0$ for which the market-clearing conditions (4.2) and (4.3) have a solution at all. For any $\mathbf{q} \in Q$, define $\gamma(\mathbf{q})=\left(\gamma_{1}(\mathbf{q}), \gamma_{2}(\mathbf{q})\right)$ as the unique pair $\left(c_{1}^{0}, c_{2}^{0}\right) \in \Re_{+}^{2}$ that solves (4.2) and (4.3) for the given price vector $\mathbf{q}$, and define

$$
\eta^{*}(\mathbf{q}):=\eta(\gamma(\mathbf{q}))
$$

as the associated effort level. Suppose that whenever households $1,2, \ldots, H$ are faced with a price vector $\mathbf{q} \in Q$, they assume that household 0's effort level is $\eta^{*}(\mathbf{q})$. The demand functions they transmit to the market are then given as

$$
\left(C_{1}^{1}(.), C_{2}^{1}(.)\right)=\left(c_{1}^{1}\left(., \eta^{*}(.)\right), c_{2}^{1}\left(., \eta^{*}(.)\right)\right)
$$


because for any $\mathbf{q} \in Q$, the consumption plan $\left(c_{1}^{1}\left(\mathbf{q}, \eta^{*}(\mathbf{q})\right), c_{2}^{1}\left(\mathbf{q}, \eta^{*}(\mathbf{q})\right)\right)$ maximizes their expected utility under the given budget constraint when they anticipate the effort level $\eta^{*}(\mathbf{q})$.

The demand functions (4.5) that households $1,2, \ldots, H$ transmit to the market determine what consumption plans household 0 can obtain through trade in the market. I refer to the set of these consumption plans as the rational-expectations offer curve of households $1,2, \ldots, H$ to household 0 . A consumption plan $\left(c_{1}^{0}, c_{2}^{0}\right)$ for household 0 is on the rational-expectations offer curve if and only if there exists a price vector $\mathbf{q} \in \boldsymbol{\Sigma}$ such that one has market clearing at $\mathbf{q}$ if, at this price vector, household 0 transmits the consumption demand $\left(c_{1}^{0}, c_{2}^{0}\right)$ to the market, i.e.,

$$
\begin{aligned}
& c_{1}^{0}+H C_{1}^{1}(\mathbf{q})=w^{0}+H w^{1}, \\
& c_{2}^{0}+H C_{2}^{1}(\mathbf{q})=w^{0}-d+H w^{1} .
\end{aligned}
$$

The following lemma shows that the set of pairs $\left(c_{1}^{0}, c_{2}^{0}\right) \in \Re_{+}^{2}$ for which a solution $\mathbf{q}>>\mathbf{0}$ to (4.6) and (4.7) can be found is just the range of the function $\gamma($.$) given by Lemma 4.1$.

Lemma 4.2 Let $\Gamma \subset \Re_{+}^{2}$ be the range of the function $\gamma($.$) , i.e., let \Gamma=$ $\gamma(Q)$. For any consumption plan $\left(c_{1}^{0}, c_{2}^{0}\right) \in \Gamma$, there exists a unique $\mathbf{q} \in Q$ such that $\left(c_{1}^{0}, c_{2}^{0}\right)=\gamma(\mathbf{q})$, i.e., the function $\gamma($.$) from Q$ to $\Gamma$ has an inverse $\mathbf{q}^{*}($.$) . For any given \left(c_{1}^{0}, c_{2}^{0}\right) \in \Gamma$, the price vector $\mathbf{q}^{*}\left(c_{1}^{0}, c_{2}^{0}\right)$ is the unique element of $Q$ for which the market-clearing conditions (4.6) and (4.7) are satisfied, and

$$
\eta^{*}\left(\mathbf{q}^{*}\left(c_{1}^{0}, c_{2}^{0}\right)\right)=\eta\left(c_{1}^{0}, c_{2}^{0}\right) .
$$

Equation (4.8) is the rational-expectations condition for households 1, 2, .., H. If the consumption plan $\left(c_{1}^{0}, c_{2}^{0}\right)$ belongs to the set $\Gamma$, the market clears at the price vector $\mathbf{q}^{*}\left(c_{1}^{0}, c_{2}^{0}\right)$. The demand vectors $\left(C_{1}^{1}\left(\mathbf{q}^{*}\left(c_{1}^{0}, c_{2}^{0}\right)\right), C_{2}^{1}\left(\mathbf{q}^{*}\left(c_{1}^{0}, c_{2}^{0}\right)\right)\right)$ of households $1,2, \ldots, H$ at this price vector are based on these households anticipating the effort level $\eta^{*}\left(\mathbf{q}^{*}\left(c_{1}^{0}, c_{2}^{0}\right)\right)$. Equation (4.8) shows that this anticipated effort level is equal to the actual effort level $\eta\left(c_{1}^{0}, c_{2}^{0}\right)$ chosen by household 0 if his consumption plan is $\left(c_{1}^{0}, c_{2}^{0}\right)$.

Lemmas 4.1 and 4.2 presume that price vectors are strictly positive. What about price vectors on the boundary of the simplex? The vector $(1,0)$ cannot be a market-clearing price vector at all: The assumptions about the functions $p_{2}(),. u($.$) , and v($.$) guarantee that p_{2}(\eta)>0$ for any $\eta<\infty$, and hence that $V\left(c_{1}^{1}, c_{2}^{1}, \eta\right)$ is everywhere strictly increasing in $c_{2}^{1}$, which implies that $c_{2}^{1}((1,0), \eta)$ is unbounded. If $p_{1}(0)=1-p_{2}(0)>0$, the same argument 
rules out the price vector $(0,1)$. However, if $p_{1}(0)=1-p_{2}(0)=0$, then for any $\left(c_{1}^{0}, c_{2}^{0}\right)$ satisfying $\eta\left(c_{1}^{0}, c_{2}^{0}\right)=0$ and $c_{2}^{0}=w^{0}-d$, the price vector $(0,1)$ will actually clear the markets.

Given these considerations, one easily sees that the conclusions of Lemma 4.2 remain valid if the sets $\Gamma$ and $Q$ are replaced by

$$
\bar{\Gamma}=\Gamma \cup\left\{c_{1}^{0} \geq 0 \mid p_{1}\left(\eta\left(c_{1}^{0}, w^{0}-d\right)\right)=0\right\} \times\left\{w^{0}-d\right\}
$$

and

$$
\bar{Q}=Q \cup \mathbf{q}^{*}(\bar{\Gamma} \backslash \Gamma),
$$

where for $\left(c_{1}^{0}, c_{2}^{0}\right) \in \bar{\Gamma} \backslash \Gamma, \mathbf{q}^{*}\left(c_{1}^{0}, c_{2}^{0}\right):=(0,1)$ and for $\mathbf{q} \in \bar{Q} \backslash Q, \eta^{*}(\mathbf{q}):=0$.

I will refer to the set $\bar{\Gamma}$ as the rational-expectations offer curve of households $1,2, \ldots, H$ to household 0 . The following result provides a simple analytical characterization.

Proposition 4.3 A consumption plan $\left(c_{1}^{0}, c_{2}^{0}\right)$ lies on the rational-expectations offer curve of households $1,2, \ldots, H$ to household 0 , i.e., $\left(c_{1}^{0}, c_{2}^{0}\right) \in \bar{\Gamma}$, if and only if

$$
\begin{gathered}
\left(1-p_{2}\left(\eta\left(c_{1}^{0}, c_{2}^{0}\right)\right)\right) v^{\prime}\left(w^{1}+\frac{1}{H}\left(w^{0}-c_{1}^{0}\right)\right)\left(c_{1}^{0}-w^{0}\right) \\
+p_{2}\left(\eta\left(c_{1}^{0}, c_{2}^{0}\right)\right) v^{\prime}\left(w^{1}+\frac{1}{H}\left(w^{0}-d-c_{2}^{0}\right)\right)\left(c_{2}^{0}-\left(w^{0}-d\right)\right)=0 .
\end{gathered}
$$

The rational-expectations offer curve is illustrated in Figure 1. The initial position $\left(w^{0}, w^{0}-d\right)$ obviously belongs to $\Gamma$. At points $\left(c_{1}^{0}, c_{2}^{0}\right)$ northwest of the initial position, the household is paying an insurance premium $\pi=w^{0}-c_{1}^{0}$ in order to receive a net-of-premium indemnity $I=c_{2}^{0}-\left(w^{0}-d\right)$ in the event of an accident. From (4.11), one finds that in this range where the household is shifting resources from state 1 to state 2 , the offer curve is actually given by a continuously differentiable function $\hat{c}_{2}($.$) relating$ $c_{2}^{0}=\hat{c}_{2}\left(c_{1}^{0}\right)$ to $c_{1}^{0}$. Equivalently, if $\pi=w^{0}-c_{1}^{0}$ is the insurance premium that household 0 is offering to the market, then $I(\pi)=\hat{c}_{2}\left(w^{0}-\pi\right)-\left(w^{0}-d\right)$ is the net-of-premium indemnity in state 2 that the market is willing to provide in return for the premium that has been offered. The indemnity-premium ratio $I(\pi) / \pi$ corresponds to the ratio $q_{1}^{*} / q_{2}^{*}$ of contingent-claims prices for the two states.

As indicated in Figure 1 below, the indemnity-premium ratio goes down as $\pi$ goes up, i.e. the (average) terms at which household 0 is getting insurance worsen as he raises the amount $\pi=w^{0}-c_{1}^{0}$ of the premium that he 
Figure 1

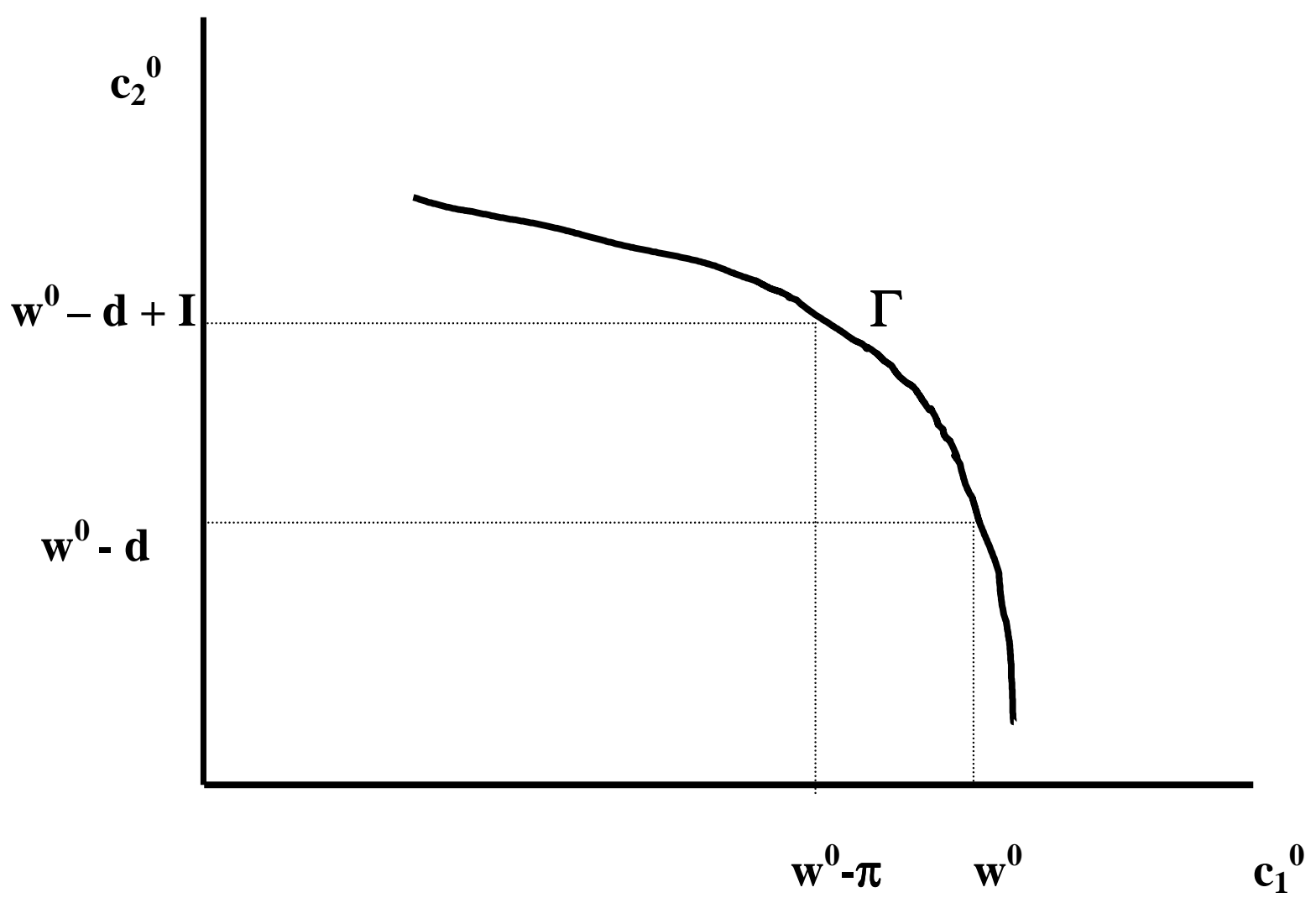


is offering to the market. There are two reasons for this effect: First, for a given assessment of household 0's accident probability, the other households' demands for consumption in state 1 are downward sloping; the larger $\pi$ is and the more consumption they already have in state 1, the smaller is their marginal willingness to pay for a further increase in their consumption in state 1 by providing additional insurance to household 0 in state 2 . Second, the other households' assessments of household 0's accident probability become more pessimistic as the household is raising the amount $\pi=w^{0}-c_{1}^{0}$ of the good in state 1 that he is offering to the market. Once the 45-degree line has been reached, incentive are as bad as they can be, and everybody expects the effortlevel to be zero.

\section{Walrasian and Cournot Rational-Expectations Equilibria}

Turning to the analysis of market equilibrium, I consider a Walrasian approach and a Cournot approach. In the Walrasian approach, all households, household 0 as well as households $1,2, . ., H$, act as price takers. In the Cournot approach, household 0 acts as a Cournot monopolist or monopsonist who is aware of the effects that his choices have on market-clearing prices.

In the Cournot approach, households $1,2, \ldots, H$ still act as price takers. There is thus an asymmetry between the treatment of household 0 and the treatment of households $1,2, \ldots, H$. This asymmetry mirrors the asymmetry between the treatment of sellers acting as oligopolists and buyers acting as price takers in the textbook partial-equilibrium Cournot model. Some such asymmetry is needed: If everybody was a Cournot oligopolist or oligopsonist announcing a fixed quantity, then for generic vectors of announcements of desired trades by the Cournot players, Walrasian auctioneer would find it impossible to clear the markets. Some other artificial device would then be needed to model the strategic interdependence between the Cournot oligopolists in terms of a well specified strategic game. ${ }^{6}$

The two approaches give rise to the following equilibrium concepts.

\footnotetext{
${ }^{6}$ In Kyle [23], the problem of inelastic excess demand functions of Cournot traders is avoided through the introduction of noise trading: To take advantage of unforeseen opportunities provided by noise traders, the Cournot traders submit elastic excess demand functions to the market. Shapley and Shubik [36] deal with the problem by having prices and trades determined through an exogenously given rule which does not hinge on the law of demand and supply and on market clearing.
} 
Definition 5.1 $A$ Walrasian rational-expectations equilibrium of the system of contingent-claims markets with moral hazard is given by a price vector $\mathbf{q}^{W}=\left(q_{1}^{W}, q_{2}^{W}\right) \in \bar{Q}$ and an allocation $\left(\left\{c_{1}^{h W}, c_{2}^{h W}\right\}_{h=0}^{H}, \eta^{W}\right)$ such that:

(i) the allocation satisfies the feasibility constraint (2.6),

(ii) $\left(c_{1}^{0 W}, c_{2}^{0 W}, \eta^{W}\right)$ maximizes $U\left(c_{1}^{0}, c_{2}^{0}, \eta\right)$ under the budget constraint $q_{1}^{W} c_{1}^{0}+q_{2}^{W} c_{2}^{0}=w^{0}-q_{2}^{W} d$, and

(iii) for $h=1, \ldots, H,\left(c_{1}^{h W}, c_{2}^{h W}\right)$ maximizes $V\left(c_{1}^{h}, c_{2}^{h}, \eta^{*}\left(\mathbf{q}^{W}\right)\right)$ under the budget constraint $q_{1}^{W} c_{1}^{h}+q_{2}^{W} c_{2}^{h}=w^{1}$.

Definition 5.2 A Cournot rational-expectations equilibrium of the system of contingent-claims markets with moral hazard is given by a price vector $\mathbf{q}^{C}=\left(q_{1}^{C}, q_{2}^{C}\right) \in \bar{Q}$ and an allocation $\left(\left\{c_{1}^{h C}, c_{2}^{h C}\right\}_{h=0}^{H}, \eta^{C}\right)$ such that:

(i) the allocation satisfies the feasibility constraint (2.6),

(ii) $\left(c_{1}^{0 C}, c_{2}^{0 C}, \eta^{C}\right)$ maximizes $U\left(c_{1}^{0}, c_{2}^{0}, \eta\right)$ subject to the constraint that $\left(c_{1}^{0}, c_{2}^{0}\right)$ belong to the rational-expectations offer curve $\bar{\Gamma}$, and

(iii) for $h=1, \ldots, H,\left(c_{1}^{h C}, c_{2}^{h C}\right)$ maximizes $V\left(c_{1}^{h}, c_{2}^{h}, \eta^{*}\left(\mathbf{q}^{C}\right)\right)$ under the budget constraint $q_{1}^{C} c_{1}^{h}+q_{2}^{C} c_{2}^{h}=w^{1}$.

The two equilibrium concepts differ only in the conditions referring to household 0 . The other conditions, i.e., the conditions referring to households $1,2, \ldots, H$ and the conditions referring to feasibility (market clearing), are the same in both concepts. In both approaches, households condition their expectations about household 0's effort level on the prices that they observe in the market. For this purpose, they rely on the function $\eta^{*}($.) that is given by (4.4); this is the point of condition (iii) in either definition. Since Lemma 4.2 implies that if the market clears at a price vector $\mathbf{q}^{*}$, then $\eta^{*}\left(\mathbf{q}^{*}\right)$ is incentive compatible, it follows that, in a Walrasian and in a Cournot rational-expectations equilibrium, the effort expectations of households $1,2, \ldots, H$ are rational. The following lemma summarizes this common feature of both equilibrium concepts.

Lemma 5.3 Let $\left(\mathbf{q}^{*},\left\{c_{1}^{h *}, c_{2}^{h *}\right\}_{h=0}^{H}, \eta^{*}\right)$ be a Walrasian or a Cournot rationalexpectations equilibrium. Then the effort level $\eta^{*}$ is incentive compatible and coincides with the expectations of households $1,2, \ldots, H$, i.e., $\eta^{*}=\eta\left(c_{1}^{0 *}, c_{2}^{0 *}\right)=$ $\eta^{*}\left(\mathbf{q}^{*}\right)$.

Condition (iii) in Definition 5.1 as well as Definition 5.2, also implies that in a Walrasian or a Cournot rational-expectations equilibrium $\left(\mathbf{q}^{*},\left\{c_{1}^{h *}, c_{2}^{h *}\right\}_{h=0}^{H}, \eta^{*}\right)$, 
one has $\left(c_{1}^{h *}, c_{2}^{h *}\right)=\left(c_{1}^{1 *}, c_{2}^{1 *}\right)$ for $h=1,2, \ldots, H$, so the equal-treatment property is satisfied. Given the feasibility condition (i), it follows that the consumption plan $\left(c_{1}^{0 *}, c_{2}^{0 *}\right)$ of household 0 satisfies (4.6) and (4.7) and hence must belong to the rational-expectations offer curve $\bar{\Gamma}$.

However, whereas a Cournot rational-expectations equilibrium plan $\left(c_{1}^{0 C}, c_{2}^{0 C}\right)$ of household 0 is chosen so as to maximize the household's expected utility over $\bar{\Gamma}$, a Walrasian rational-expectations equilibrium plan $\left(c_{1}^{0 W}, c_{2}^{0 W}\right)$ is chosen to maximize household's expected utility under the budget constraint determined by the market-clearing price vector $\mathbf{q}^{W}$. The implications of these different specifications are shown in the following results.

Proposition 5.4 If $\left(\mathbf{q}^{W},\left\{c_{1}^{h W}, c_{2}^{h W}\right\}_{h=0}^{H}, \eta^{W}\right)$ is a Walrasian rational-expectations equilibrium, then

$$
\begin{gathered}
\eta^{W}>0, \\
w^{0}-d<c_{2}^{0 W}<c_{1}^{0 W}<w^{0}, \\
c_{2}^{h}<w^{1}<c_{1}^{h},
\end{gathered}
$$

and

$$
\frac{u^{\prime}\left(c_{1}^{0 W}\right)}{u^{\prime}\left(c_{2}^{0 W}\right)}=\frac{v^{\prime}\left(c_{1}^{h W}\right)}{v^{\prime}\left(c_{2}^{h W}\right)}
$$

for $h=1,2, \ldots, H$. Moreover, the equilibrium allocation $\left(\left\{c_{1}^{h}, c_{2}^{h}\right\}_{h=0}^{H}, \eta\right)$ is Pareto-dominated by a feasible, incentive-compatible allocation $\left(\left\{\hat{c}_{1}^{h}, \hat{c}_{2}^{h}\right\}_{h=0}^{H}, \hat{\eta}\right)$ satisfying $\hat{c}_{1}^{0}>c_{1}^{0}$ and $\hat{\eta}=\eta\left(\hat{c}_{1}^{0}, \hat{c}_{2}^{0}\right)>\eta$.

Proposition 5.5 If $\left(\mathbf{q}^{C},\left\{c_{1}^{h C}, c_{2}^{h C}\right\}_{h=0}^{H}, \eta^{C}\right)$ is a Cournot rational-expectations equilibrium, then

$$
\begin{gathered}
\eta^{C}>0, \\
w^{0}-d<c_{2}^{0 C}<c_{1}^{0 C}<w^{0}, \\
c_{2}^{h C}<w^{1}<c_{1}^{h C},
\end{gathered}
$$

and

$$
\frac{u^{\prime}\left(c_{1}^{0 C}\right)}{u^{\prime}\left(c_{2}^{0 C}\right)}<\frac{v^{\prime}\left(c_{1}^{h C}\right)}{v^{\prime}\left(c_{2}^{h C}\right)}
$$

for $h=1,2, \ldots, H$. 
Proposition 5.4 represents the traditional notion that in the presence of moral hazard Walrasian insurance markets with price taking generate too much insurance and too little effort (Pauly [31]). When all agents take contingent-claims prices as given, the Walrasian-equilibrium risk allocation satisfies Borch's [8] condition (5.4) for an efficient risk allocation at a given accident probability. However the effects of the risk allocation on the chosen effort level and on the accident probability are not taken into account so, starting from a Walrasian rational-expectations equilibrium allocation, a small change in the risk allocation which increases effort incentives will unambiguously improve the allocation. Whereas the welfare effects of the change in the risk allocation as such are on the second order of smalls, the improved effort incentives provide first-order gains.

In contrast, as a strategic player à la Cournot, household 0 chooses to obtain less insurance than would be called for by Borch's condition. The inequality (5.8) results from two considerations:

- As household 0 raises his demand for state 2 consumption/lowers his demand for state 1 consumption, he lowers the equilibrium amount of state 2 consumption/raises the equilibrium amount of state 1 consumption of the other households. This affects the other households' marginal utilities of consumption in the two states and worsens the terms of trade available to household 0 .

- As household 0 raises his demand for state 2 consumption/lowers his demand for state 1 consumption, he also worsens his own effort incentives and thereby raises the probability of an accident (state 2). Through the rational-expectations condition $\eta^{*}\left(\mathbf{q}^{*}\left(c_{1}^{0}, c_{2}^{0}\right)\right)=\eta\left(c_{1}^{0}, c_{2}^{0}\right)$, the other households take this incentive effect into account, which provides for an additional worsening of the terms of trade available to household 0 .

Both effects induce household 0 to restrict the exchange of contingent claims to a lower level than would be called for by Borch's condition. He thereby avoids the extreme form of overinsurance that is associated with Walrasian rational-expectations equilibrium. Whether a Cournot rationalexpectations equilibrium involves overinsurance at all is unclear. Depending on the data of the model, there may be over- or underinsurance. On the one hand, there is a tendency towards underinsurance due to the standard monopoly effect keeping the household's insurance demand down. On the other hand, there is a tendency towards overinsurance due to the household's neglecting the externality that his trading partners suffer when his effort 
incentives are reduced. Depending on the data of the model, one or the other tendency may dominate, or they may just cancel each other, in which case an equilibrium allocation may even be second-best. Unfortunately, no simple data classification seems available to indicate when Cournot rationalexpectations equilibria involve over- or underinsurance.

\section{Cournot Convergence}

The difference between Walrasian and Cournot rational-expectations equilibria is most pronounced when there are many agents subdividing the insurance buyer's risk. In this case, any one of the insurance providers has only a small share of the risk, and their marginal utilities of consumption are fairly insensitive to the quantities chosen by household 0. Market-clearing prices of contingent claims therefore reflect the state probabilities with little adjustment for the state dependence of marginal utilities. At the odds determined by the insurance buyer's effort against accidents, the price of insurance is approximately fair.

In the Walrasian approach, there are then two possibilities. Either household 0 as a price taker obtains approximately full insurance and chooses an effort level close to zero, or an equilibrium fails to exist. An equilibrium fails to exist if the accident probability corresponding to zero effort is close to one. If the accident probability anticipated by the other market participants is close to one, insurance is very expensive. If insurance is very expensive, the insurance buyer is better off not buying any insurance at all, but instead taking care against the possibility of an accident. The two conditions that, at the effort level chosen by the insurance buyer, the price of insurance be approximately fair and that the consumption plan and effort level chosen by the insurance buyer maximize his expected utility at the given price vector are mutually inconsistent. ${ }^{7}$ These considerations yield:

Proposition 6.1 There exists $\varepsilon>0$ such that if $p_{2}(0) \geq 1-\varepsilon$, then a Walrasian rational-expectations equilibrium fails to exist whenever $H$ is suf-

\footnotetext{
${ }^{7}$ Technically, nonexistence of equilibrium is due to the fact that moral hazard destroys the convexity of indifference curves. With convex indifference curves, the marginal willingness to pay for additional consumption in state 2 , is a decreasing function of the amount of insurance that one already has. Without moral hazard, this convexity property follows from the strict concavity of the von Neumann-Morgenstern utility function. With moral hazard, this convexity property can fail because the more insurance one buys, the less care one takes against accidents, the higher is the probability of an accident, and the more one is willing to pay for an additional unit of consumption in the event of an accident; see Helpman and Laffont [19].
} 
ficiently large. If, for $H=1,2, \ldots,\left(\mathbf{q}^{W H},\left\{c_{1}^{h W H}, c_{2}^{h W H}\right\}_{h=0}^{H}, \eta^{W H}\right)$ is a Walrasian rational-expectations equilibrium, then

$$
\lim _{H \rightarrow \infty} c_{1}^{0 W H}=\lim _{H \rightarrow \infty} c_{2}^{0 W H}=w^{0}-p(0) d, \quad \lim _{H \rightarrow \infty} \eta^{W H}=0,
$$

and

$$
\lim _{H \rightarrow \infty} \mathbf{q}^{W H}=\left(1-p_{2}(0), p_{2}(0)\right)
$$

In contrast, for Cournot rational-expectations equilibria, one finds:

Proposition 6.2 For $H=1,2, \ldots$, a Cournot rational-expectations equilibrium $\left(\mathbf{q}^{C H},\left\{c_{1}^{h C H}, c_{2}^{h C H}\right\}_{h=0}^{H}, \eta^{C H}\right)$ exists. If $\left(\mathbf{q}^{*}, c_{1}^{0 *}, c_{2}^{0 *}, \eta^{*}\right)$ is a limit point of a sequence $\left\{\left(\mathbf{q}^{C H}, c_{1}^{0 C H}, c_{2}^{0 C H}, \eta^{C H}\right)\right\}_{H=1}^{\infty}$ of Cournot rational-expectations equilibria, then

$$
\mathbf{q}^{*}=\left(1-p_{2}\left(\eta^{*}\right), p_{2}\left(\eta^{*}\right)\right),
$$

and $\left(c_{1}^{0 *}, c_{2}^{0 *}, \eta^{*}\right)$ maximizes $U\left(c_{1}^{0}, c_{2}^{0}, \eta\right)$ under the constraint

$$
\left(1-p_{2}\left(\eta\left(c_{1}^{0}, c_{2}^{0}\right)\right)\right) c_{1}^{0}+p_{2}\left(\eta\left(c_{1}^{0}, c_{2}^{0}\right)\right) c_{2}^{0} \leq w^{0}-p_{2}\left(\eta\left(c_{1}^{0}, c_{2}^{0}\right)\right) d .
$$

Proposition 6.2 contains the main insight of this paper. If $H$ is large, the maximization problem of household 0 in a Cournot rational-expectations equilibrium is similar to the second-best allocation problem for an economy with an arbitrary number of risk neutral insurers. Any limit point of a sequence of Cournot rational-expectations equilibrium outcomes for household 0 must therefore be a solution to this second-best allocation problem. By Proposition 3.2, it follows that, for large $H$, any Cournot rationalexpectations equilibrium allocation provides the market participants with payoffs that are close to their payoffs from some second-best allocation. If the solution to the "limit problem" of maximizing $U\left(c_{1}^{0}, c_{2}^{0}, \eta\right)$ subject to (6.4) is unique, then for large $H$, Cournot rational-expectations equilibrium allocations will actually be close to second-best allocations.

Underlying this result is the fundamental fact that trade with household 0 does not generate any surplus for the other market participants if this household is insignificant relative to the market. This "no surplus property" is well known from the literature on Cournot convergence in markets without moral hazard or asymmetric information $([14,15])$. From that literature we know that the convergence of Cournot outcomes to efficient outcomes has less to do with numbers of Cournot oligopolists becoming large than with 
perceived demand curves becoming infinitely elastic and the other participants' surplus from trading with a Cournot trader going to zero. In the present setting, an effect of perceived demand curves becoming infinitely elastic would be observed if there was no moral hazard and household 0's effort level was exogenously fixed at some $\hat{\eta}>0$. In this case, for large $H$, the market offer curve would become infinitely elastic at prices corresponding to the probabilities $p_{1}(\hat{\eta}), p_{2}(\hat{\eta})$. Risk premia obtained by the other households for accommodating household 0's trades go to zero as $H$ becomes large.

With endogenous effort choices, the rational-expectations offer curve does not become infinitely elastic when $H$ becomes large. The dependence of market-clearing prices on the Cournot trader's quantity choices reflects not only changes in risk premia required to accommodate these quantity choices in the market, but also reflects the changing assessments of effort incentives that go with the different quantity choices. In contrast to the dependence of required risk premia on the Cournot trader's choices, this latter effect persists even when $H$ becomes large and the insurance buyer becomes insignificant relative to the market.

Why then do Cournot outcomes converge to second-best outcomes even though the Cournot trader remains far from being a price-taker? Remarkably, a limiting "no surplus property" holds even though the rational-expectations offer curve does not become infinitely elastic. To verify this property, recall that Cournot rational-expectations equilibria have the equal-treatment property. For any $\left(c_{1}^{0 H}, c_{2}^{0 H}\right) \in \bar{\Gamma}^{H}$, let $w^{H}\left(c_{1}^{0 H}, c_{2}^{0 H}\right)$ be defined by the equation

$$
\begin{aligned}
v\left(w^{H}\left(c_{1}^{0 H}, c_{2}^{0 H}\right)\right)= & \left(1-p_{2}\left(\eta\left(c_{1}^{0}, c_{2}^{0}\right)\right)\right) v\left(w^{1}-\frac{1}{H}\left(c_{1}^{0 H}-w^{0}\right)\right) \\
& +p_{2}\left(\eta\left(c_{1}^{0}, c_{2}^{0}\right)\right) v\left(w^{1}-\frac{1}{H}\left(c_{2}^{0 H}-w^{0}+d\right)\right) .
\end{aligned}
$$

Then $w^{H}\left(c_{1}^{0 H}, c_{2}^{0 H}\right)$ is the certainty equivalent for households $1,2, \ldots, H$ of the outcome they obtain when household 0 chooses the consumption plan $\left(c_{1}^{0 H}, c_{2}^{0 H}\right)$, and $H\left(w^{H}\left(c_{1}^{0 H}, c_{2}^{0 H}\right)-w^{1}\right)$ is a measure of the aggregate surplus obtained by these households. The concavity of $v($.$) implies that$

$$
\begin{gathered}
H\left(w^{H}\left(c_{1}^{0 H}, c_{2}^{0 H}\right)-w^{1}\right) \leq H \frac{v\left(w^{H}\left(c_{1}^{0 H}, c_{2}^{0 H}\right)\right)-v\left(w^{1}\right)}{v^{\prime}\left(w^{H}\left(c_{1}^{0 H}, c_{2}^{0 H}\right)\right)} \\
\leq \frac{v^{\prime}\left(w_{1}\right)}{v^{\prime}\left(w^{H}\left(c_{1}^{0 H}, c_{2}^{0 H}\right)\right)}\left[\left(1-p_{2}\left(\eta\left(c_{1}^{0}, c_{2}^{0}\right)\right)\right)\left(c_{1}^{0 H}-w^{0}\right)+p_{2}\left(\eta\left(c_{1}^{0}, c_{2}^{0}\right)\right)\left(c_{2}^{0 H}-w^{0} d\right)\right] .
\end{gathered}
$$

As $H$ becomes large and the rational expectations offer curve $\bar{\Gamma}^{H}$ converges to the set of consumption plans satisfying (6.4) with equality, the right 
hand of this inequality converges to zero, uniformly over $\left(c_{1}^{0 H}, c_{2}^{0 H}\right)$. Thus as $H$ becomes large, the measure $H\left(w^{H}\left(c_{1}^{0 H}, c_{2}^{0 H}\right)-w^{1}\right)$ of aggregate surplus converges to zero, regardless of $\left(c_{1}^{0 H}, c_{2}^{0 H}\right)$.

Given this limiting "no surplus property", asymptotically, the choices of household 0 concern only himself. Because all surplus from his trading with the other participants accrues to him, he has no more incentive to distort his quantity choices away from second-best efficiency. Whereas he retains the power to influence market-clearing prices, he does not retain any power to affect the utility levels attained by the other participants or the distribution of surplus from his trading in the market. The analysis thus confirms the suggestion of Ostroy [30] and Makowski $[25,26]$ that the "no surplus property" provides a more fundamental characterization of "perfect competition" than price taking.

\section{Cournot Convergence with Multiple Insurance Buyers}

The analysis so far has involved just one insurance buyer and $H$ insurers. In this final substantive section of the paper I show that a model with $m$ insurance buyers and $m H$ insurers generates roughly the same kind of Cournot convergence even if $m$ rather than $H$ is taken to go out of bounds.

To model accident risks and moral hazard in an economy with $m$ insurance buyers, households $01, \ldots, 0 m$, and $m H$ insurers, households $11, \ldots H m$, let $(\Omega, \Sigma, \nu)$ be some underlying probability space and, for $i=1, \ldots, m$, let $\tilde{a}_{i}$ be some exogenous random variable on $(\Omega, \mathcal{S}, \nu)$ so that, if household $0 i$ chooses the effort level $\eta$, then his endowment in the state $\omega \in \Omega$ is given as

$$
\tilde{e}^{0 i}(\omega, \eta)=w^{0} \text { if } \tilde{a}_{i}(\omega) \leq \eta
$$

and

$$
\tilde{e}^{0 i}(\omega, \eta)=w^{0}-d \text { if } \tilde{a}_{i}(\omega)>\eta .
$$

Then the probabilities of the events $E_{1}^{0 i}=\left\{\omega \in \Omega \mid \tilde{e}^{0 i}(\omega, \eta)=w^{0}\right\}$, where household $0 i$ does not have an accident, and $E_{2}^{0 i}=\left\{\omega \in \Omega \mid \tilde{e}^{0 i}(\omega, \eta)=\right.$ $\left.w^{0}-d\right\}$, where he does have an accident, depend on $\eta$ and can be written as

$$
\nu\left(E_{1}^{0 i}\right)=p_{1}^{i}(\eta):=\nu\left(\left\{\omega \in \Omega \mid \tilde{a}_{i}(\omega) \leq \eta\right\}\right)
$$

and

$$
\nu\left(E_{2}^{0 i}\right)=p_{2}^{i}(\eta):=\nu\left(\left\{\omega \in \Omega \mid \tilde{a}_{i}(\omega)>\eta\right\}\right) .
$$


The random variables $\tilde{a}_{1}, \ldots, \tilde{a}_{m}$ are assumed to be independent and identically distributed. Therefore the functions $p_{1}^{i}($.$) and p_{2}^{i}($.$) are the same for$ all $i$ and the superscript can be dropped. For simplicity, I also assume that households $01, \ldots, 0 m$ all have the same von Neumann-Morgenstern utility $u(c)-\eta$ of consumption $c$ and effort $\eta$, and that households $11, \ldots H m$ all have the same von Neumann-Morgenstern utility function $v($.$) and the same$ state-independent endowment $w^{1}>0$. The functions $u(),. p_{1}(),. p_{2}($.$) , and$ $v($.$) have the same properties as in the preceding analysis.$

The effort levels $\eta^{1}, \ldots, \eta^{m}$ as well as the realizations of the random variables $\tilde{a}_{1}, \ldots \tilde{a}_{m}$ are unobservable so no contracts can be written on them. However the realizations of the endowment random variables $\tilde{e}^{0 i}$ are observable and verifiable. Therefore one can write contracts for contingent claims on events such as $E_{1}^{0 i}$ and $E_{2}^{0 i}$, which are defined with reference to the endowment random variables $\tilde{e}^{0 i}$. As before, these claims are traded in organized Walrasian markets.

The model is now more complicated than before because there are more markets, more strategic traders and more sources of moral hazard. The system of contingent-claims markets will include markets on events whose definitions involve more than one household, such as the event $\cap_{i=1}^{m} E_{1}^{0 i}$, where $n o$ household has an accident, or the event $\cap_{i=1}^{[m / 2]} E_{2}^{02 i}$, where all evennumbered households have an accident and all odd-numbered households do not. If $E=\left\{w^{0}, w^{0}-d\right\}^{m}$ is the space of vectors of possible endowment realizations of households $01, \ldots, 0 m$, then any vector $\mathbf{e} \in E$ can be thought of as defining an elementary event on which contingent claims may be written. A complete market system involves markets for contingent claims on all elementary events. Any other event, e.g., the event $E_{2}^{0 i}$ where household $i$ has an accident, can be thought of as a union of elementary events.

For a given vector $\boldsymbol{\eta}=\left(\eta^{1}, \ldots, \eta^{m}\right)$ of effort levels, the elementary event defined by the vector $\mathbf{e} \in E$ has the probability

$$
\pi(\mathbf{e}, \boldsymbol{\eta}):=\prod_{i=1}^{m} p_{s_{i}(\mathbf{e})}\left(\eta^{i}\right),
$$

where, for $i=1, \ldots, m$,

$$
s_{i}(\mathbf{e})=1 \text { if } e^{0 i}=w^{0} \text { and } s_{i}(\mathbf{e})=2 \text { if } e^{0 i}=w^{0}-d .
$$

If household $h j, h=1, \ldots, H, j=1, \ldots, m$ expects the effort vector $\boldsymbol{\eta}=$ $\left(\eta^{1}, \ldots, \eta^{m}\right)$ from households $01, \ldots, 0 m$, his expected utility from a net-trade plan $\{z(\mathbf{e})\}_{\mathbf{e} \in E}$ for contingent claims on the different elementary events is 
given as

$$
\sum_{\mathbf{e} \in E} \pi(\mathbf{e}, \boldsymbol{\eta}) v\left(w^{1}+z(\mathbf{e})\right)
$$

Given the vector $\boldsymbol{\eta}$ of anticipated effort choices, household $h j$ would be choosing his net-trade plan to maximize (7.7) subject to the budget constraint

$$
\sum_{\mathbf{e} \in E} q(\mathbf{e}) z(\mathbf{e})=0
$$

where $q(\mathbf{e})$ is the price of a claim contingent on the elementary event defined by $\mathbf{e}$. If $q(\mathbf{e})>0$ for all $\mathbf{e} \in E$, the solution to this problem is unique. The net-trade plan which solves this maximization problem is denoted as $\{z(\mathbf{e} \mid \mathbf{q}, \boldsymbol{\eta})\}_{\mathbf{e} \in E}$. Without loss of generality, the price system $\mathbf{q}=\{q(\mathbf{e})\}_{\mathbf{e} \in E}$ is taken to belong to the nonnegative simplex $\Sigma:=\left\{\{q(e)\}_{\mathbf{e} \in E} \in \Re_{+}^{2^{m}} \mid \sum_{\mathbf{e} \in E} q(\mathbf{e})=\right.$ $1\}$. I write $\mathbf{q}>>\mathbf{0}$ if $q(\mathbf{e})>0$ for all $\mathbf{e} \in E$.

As before, the question is to what extent the insurance buyers' effort levels can be inferred from market-clearing prices. Answering this question is more difficult than before because market-clearing prices only convey information about the aggregate of the insurance buyers' positions. To infer individual effort levels from this information, the insurance sellers must form beliefs about the decomposition of the aggregate into individual positions.

A full treatment of this issue is beyond the scope of this paper. For a simplified treatment, I impose the - admittedly arbitrary - assumption that households $01, \ldots, 0 \mathrm{~m}$ refrain from selling insurance to each other as well as buying insurance from households $11, \ldots, H$ m. Household $0 i$ buys or sells claims on the events $E_{1}^{0 i}$ and $E_{2}^{0 i}$, but not, e.g., on the event $E_{1}^{0 i} \cap E_{2}^{0 j}$ which depends on the accident incidence of household $0 j$ as well as household $0 i$. Formally, a net-trade plan $\left\{z^{0 i}(\mathbf{e})\right\}_{\mathbf{e} \in E}$ of household $0 i$ is required to satisfy the measurability condition that $z^{0 i}(\mathbf{e})=z^{0 i}(\hat{\mathbf{e}})$ whenever $s_{i}(\mathbf{e})=s_{i}(\hat{\mathbf{e}})$. Under this condition, the net-trade plan $\left\{z^{0 i}(\mathbf{e})\right\}_{\mathbf{e} \in E}$ is characterized by two numbers $z_{1}^{0 i}, z_{2}^{0 i}$ such that $z^{0 i}(\mathbf{e})=z_{1}^{0 i}$ if $s_{i}(\mathbf{e})=1$ and $z^{0 i}(\mathbf{e})=z_{2}^{0 i}$ if $s_{i}(\mathbf{e})=2$. Moreover, one has

$$
z_{1}^{0 i}-z_{2}^{0 i}=\sum_{j=1}^{m}\left[z^{0 j}(\overline{\mathbf{e}})-z^{0 j}(\hat{\mathbf{e}})\right]
$$

for any two elementary events $\overline{\mathbf{e}}, \hat{\mathbf{e}} \in E$ such that $s_{i}(\overline{\mathbf{e}})=1, s_{i}(\hat{\mathbf{e}})=2$, and $s_{j}(\overline{\mathbf{e}})=s_{j}(\hat{\mathbf{e}})$ for all $j \neq i$. Given the budget constraint $\sum_{\mathbf{e} \in E} q(\mathbf{e}) z_{s_{i}(\mathbf{e})}^{0 i}=$ 0 , this property is sufficient for anybody to infer the individual positions 
of households $01, \ldots, 0 m$ from the aggregates $\sum_{j=1}^{m} z^{0 j}(\mathbf{e}), \mathbf{e} \in E .^{8}$ This decomposition of aggregates into individual positions provides the key to the following generalization of Lemma 4.1 to the case of multiple insurance buyers.

Lemma 7.1 For any $\mathbf{q} \in \Sigma$ such that $\mathbf{q}>>0$, there exists at most one vector $\left\{\left(z_{1}^{0 i}, z_{2}^{0 i}\right)\right\}_{i=1}^{m} \in \Re^{2 m}$ such that

$$
\sum_{\mathbf{e} \in E} q(\mathbf{e}) z_{s_{i}(\mathbf{e})}^{0 i}=0
$$

for $i=1, \ldots, m$, and

$$
\sum_{i=1}^{m} z_{s_{i}(\mathbf{e})}^{0 i}+H m z\left(\mathbf{e} \mid \mathbf{q}, \boldsymbol{\eta}\left(\left\{\left(z_{1}^{0 i}, z_{2}^{0 i}\right)\right\}_{i=1}^{m}\right)\right)=0
$$

for all $\mathbf{e} \in E$, where

$\boldsymbol{\eta}\left(\left\{\left(z_{1}^{0 i}, z_{2}^{0 i}\right)\right\}_{i=1}^{m}\right):=\left(\eta\left(w^{0}+z_{1}^{01}, w^{0}-d+z_{2}^{01}\right), \ldots, \eta\left(w^{0}+z_{1}^{0 m}, w^{0}-d+z_{2}^{0 m}\right)\right)$.

Lemma 4.2 is similarly generalized. Proceeding as before, let $Q \subset \Sigma$ be the set of price systems $\mathbf{q}>>0$ for which a vector $\left\{\left(z_{1}^{0 i}, z_{2}^{0 i}\right)\right\}_{i=1}^{m}$ of net-trade plans satisfying (7.9) - (7.11) exists. For any $\mathbf{q} \in Q$, let $\boldsymbol{\xi}(\mathbf{q})=$ $\left(\left\{\xi_{1}^{0 i}(\mathbf{q}), \xi_{2}^{0 i}(\mathbf{q})\right\}\right)$ be the unique net-trade vector satisfying $(7.9)-(7.11)$, and let

$$
\boldsymbol{\eta}^{*}(\mathbf{q}):=\boldsymbol{\eta}(\boldsymbol{\xi}(\mathbf{q}))
$$

be the associated vector of effort levels. Again one may suppose that whenever households $11, \ldots, H m$ are faced with a price system $\mathbf{q} \in Q$, they assume that the vector of effort levels of households $01, \ldots 0 \mathrm{~m}$ is $\eta^{*}(\mathbf{q})$ and transmit the net-trade plans $\left\{z\left(\mathbf{e} \mid \mathbf{q}, \boldsymbol{\eta}^{*}(\mathbf{q})\right)\right\}_{\mathbf{e} \in E}$ to the market.

\footnotetext{
${ }^{8}$ Without the additional restriction on insurance buyers' net-trade plans, the inference from aggregates to individual positions would involve some arbitrariness. At an equilibrium outcome, this arbitrariness would be resolved by the requirement of rational expectations. For deviations away from the Cournot traders' equilibrium choices, there would seem to be room for a multiplicity of off-the-equilibrium path beliefs of the insurance sellers. The problem is akin to the problem of specifying off-the-equilibrium-path beliefs in extensive-form games.
} 
Lemma 7.2 Let $\Xi \subset \Re^{2 m}$ be the range of the function $\boldsymbol{\xi}($.$) , i.e., let \Xi=$ $\boldsymbol{\xi}(Q)$. For any vector $\left\{\left(z_{1}^{0 i}, z_{2}^{0 i}\right)\right\}_{i=1}^{m}$ of net-trade plans in $\Xi$, there exists a unique $\mathbf{q} \in Q$ such that $\left\{\left(z_{1}^{0 i}, z_{2}^{0 i}\right)\right\}_{i=1}^{m}=\boldsymbol{\xi}(\mathbf{q})$, i.e., the function $\boldsymbol{\xi}($.$) from Q$ to $\Xi$ has an inverse $\mathbf{q}^{*}($.$) . For any given \left\{\left(z_{1}^{0 i}, z_{2}^{0 i}\right)\right\}_{i=1}^{m} \in \Xi$, the price system $\mathbf{q}^{*}\left(\left\{\left(z_{1}^{0 i}, z_{2}^{0 i}\right)\right\}_{i=1}^{m}\right)$ is the unique element of $Q$ for which

$$
\sum_{i=1}^{m} z_{s_{i}(\mathbf{e})}^{0 i}+H m z\left(\mathbf{e} \mid \mathbf{q}, \boldsymbol{\eta}^{*}(\mathbf{q})\right)=0
$$

for all $\mathbf{e} \in E$. Moreover,

$$
\boldsymbol{\eta}^{*}\left(\mathbf{q}^{*}\left(\left\{\left(z_{1}^{0 i}, z_{2}^{0 i}\right)\right\}_{i=1}^{m}\right)\right)=\boldsymbol{\eta}\left(\left\{\left(z_{1}^{0 i}, z_{2}^{0 i}\right)\right\}_{i=1}^{m}\right) .
$$

Like Lemmas 4.1 and 4.2, Lemmas 7.1 and 7.2 presume that price vectors are strictly positive. Price vectors on the boundary of the set $\Sigma^{2^{m}}$ can be handled in the same way as in the case $m=1$. However, to avoid this complication, I simply assume that $p_{1}(0)>0$ and therefore $p_{1}(\eta)>0$ for all $\eta$. The assumptions on the functions $p_{1}($.$) and p_{2}($.$) also imply that$ $p_{2}(\eta)=1-p_{1}(\eta)>0$ for all $\eta$. For any $\mathbf{q} \in \Sigma$ and any $\boldsymbol{\eta}=\left(\eta^{1}, \ldots, \eta^{m}\right) \in \Re_{+}^{m}$ then, the problem of maximizing (7.7) under the constraint (7.8) has a solution only if the price vector $\mathbf{q}$ is strictly positive. A price vector $\mathbf{q}$ on the boundary of $\Sigma^{m}$ never clears the markets, and one may identify the rational-expectations offer curve of households $11, \ldots H m$, insurance sellers, to households $01, \ldots, 0 \mathrm{~m}$, the insurance buyers, with the set $\Xi$ that is defined through Lemmas 7.1 and 7.2. Using the first-order conditions for the determination of $z\left(\mathbf{e} \mid \mathbf{q}, \boldsymbol{\eta}\left(\left\{\left(z_{1}^{0 i}, z_{2}^{0 i}\right)\right\}_{i=1}^{m}\right)\right)$, one obtains the following generalization of the characterization of $\Xi$ in Proposition 4.3.

Proposition 7.3 A vector $\left\{\left(z_{1}^{0 i}, z_{2}^{0 i}\right)\right\}_{i=1}^{m}$ of net-trade plans of households $01, \ldots, 0 \mathrm{~m}$ lies on the rational-expectations offer curve of households $11, \ldots, \mathrm{Hm}$ if and only if

$$
\sum_{\mathbf{e} \in E} \pi\left(\mathbf{e}, \boldsymbol{\eta}\left(\left\{\left(z_{1}^{0 j}, z_{2}^{0 j}\right)\right\}_{j=1}^{m}\right)\right) v^{\prime}\left(w^{1}-\frac{1}{m H} \sum_{k=1}^{m} z_{s_{k}(\mathbf{e})}^{0 k}\right) z_{s_{i}(\mathbf{e})}^{0 i}=0
$$

for $i=1, \ldots m$. 
The problem of an insurance buyer in the model with $m>1$ is the same as in the model with $m=1 .{ }^{9}$ He chooses a net-trade plan $\left(z_{1}^{0 i}, z_{2}^{0 i}\right)$ and effort level $\eta^{i}$ to maximize $U\left(w^{0}+z_{1}^{0 i}, w^{0}-d+z_{2}^{0 i}, \eta^{i}\right)$ under whatever constraints the market imposes on his choice of $\left(z_{1}^{0 i}, z_{2}^{0 i}\right)$. In the Cournot approach, his opportunity set is determined by the rational-expectations offer curve $\Xi$.

Definition 7.4 A Cournot rational-expectations equilibrium of the system of contingent-claims markets with moral hazard is given by a price system $\mathbf{q}^{C} \in Q$ and an array $\left\{z_{1}^{0 i C}, z_{2}^{0 i C}, \eta^{i C}\right\}_{i=1}^{m}$ of net-trade plans and effort choices of households $01, \ldots 0 \mathrm{~m}$ such that, for any $i$, the triple $\left(z_{1}^{0 i C}, z_{2}^{0 i C}, \eta^{i C}\right)$ maximizes $U\left(w^{0}+z_{1}^{0 i}, w^{0}-d+z_{2}^{0 i}, \eta\right)$ subject to the constraint that $\left(\left(z_{1}^{0 i}, z_{2}^{0 i}\right),\left\{z_{1}^{0 j C}, z_{2}^{0 j C}\right\}_{j \neq i}\right)$ belong to the rational-expectations offer curve $\Xi$.

In contrast to Definition 5.2, Definition 7.4 refers only to the Cournot players. The analogues of conditions (i) and (iii) of Definition 5.2 are implicit in the requirement that the array $\left\{z_{1}^{0 i C}, z_{2}^{0 i C}\right\}_{i=1}^{m}$ belong to the rationalexpectaitons offer curve; therefore they are not stated explicitly.

To bring out the similarity between the insurance buyers problems in Definitions 7.4 and 5.2, it is useful to reformulate the constraint on the net trade vectors available to household $0 i$. By (7.5) and Proposition 7.3, the constraint that the array $\left(\left(z_{1}^{0 i}, z_{2}^{0 i}\right),\left\{z_{1}^{0 j C}, z_{2}^{0 j C}\right\}_{j \neq i}\right)$ belong to the rationalexpectations offer curve $\Xi$ is equivalent to the requirement that $\left(z_{1}^{0 i}, z_{2}^{0 i}\right)$ and $\left\{z_{1}^{0 j C}, z_{2}^{0 j C}\right\}_{j \neq i}$ satisfy the equation

$$
\begin{array}{r}
p_{1}\left(\eta^{i}\left(w^{0}+z_{1}^{0 i}, w^{0}-d+z_{2}^{0 i}\right)\right) z_{1}^{0 i} \varphi\left(z_{1}^{0 i},\left\{z_{1}^{0 j C}, z_{2}^{0 j C}\right\}_{j \neq i}, \boldsymbol{\eta}_{-i}^{C}\right) \\
+p_{2}\left(\eta^{i}\left(w^{0}+z_{1}^{0 i}, w^{0}-d+z_{2}^{0 i}\right)\right) \varphi\left(z_{2}^{0 i},\left\{z_{1}^{0 j C}, z_{2}^{0 j C}\right\}_{j \neq i}, \boldsymbol{\eta}_{-i}^{C}\right) z_{2}^{0 i}=0,
\end{array}
$$

where $\boldsymbol{\eta}_{-i}^{C}=\left\{\eta^{k}\left(w^{0}+z_{1}^{0 k C}, w^{0}-d+z_{2}^{0 k C}\right)\right\}_{k \neq i}$ is the vector of effort levels of households $0 k, k \neq i$, and for $s=1,2$,

$$
\begin{gathered}
\varphi\left(z_{s}^{0 i},\left\{z_{1}^{0 j C}, z_{2}^{0 j C}\right\}_{j \neq i}, \boldsymbol{\eta}_{-i}^{C}\right):= \\
\sum_{\mathbf{e}_{-i} \in E_{-i}} \pi\left(\mathbf{e}_{-i}, \boldsymbol{\eta}_{-i}^{C}\right) v^{\prime}\left(w^{1}-\frac{1}{m H}\left(\sum_{k \neq i} z_{s_{k}\left(\mathbf{e}_{-i}\right)}^{0 k C}+z_{s}^{0 i}\right)\right) .
\end{gathered}
$$

\footnotetext{
${ }^{9}$ In contrast, if household $0 i$ was also selling insurance to households $0 j,, j \neq i$, he would also be worrying about the other insurance buyers' effort incentives. Like households $11, . . H m$, he might then want to transmit an excess demand function to the market rather than an excess demand vector.
} 
In (7.17), $E_{-i}=\left\{w^{0}, w^{0}-d\right\}^{m-1}$ is the set of vectors of possible endowment realizations of households $0 k, k \neq i$, and, for any $\mathbf{e}_{-i} \in E_{-i}, \pi\left(\mathbf{e}_{-i}, \boldsymbol{\eta}_{-i}^{C}\right)$ is the probability of $\mathbf{e}_{-i}$ occurring if the effort vector is $\boldsymbol{\eta}_{-i}^{C}$. Upon comparing (7.16) with (4.11), one sees that these constraints on the insurance buyers' net-trades have the same structure, except that, in (7.16), the marginal utilities $v^{\prime}\left(w^{1}+\frac{1}{H}\left(w^{0}-c_{1}^{0}\right)\right)$ and $v^{\prime}\left(w^{1}+\frac{1}{H}\left(w^{0}-d-c_{2}^{0}\right)\right)$ in (4.11) are replaced by the expected marginal utilities $\varphi\left(z_{s}^{0 i},\left\{z_{1}^{0 j C}, z_{2}^{0 j C}\right\}_{j \neq i}, \boldsymbol{\eta}_{-i}^{C}\right)$ which also depend on the insurers' aggregate net trades with the other insurance buyers.

Given the structural similarity of (7.16) with (4.11), one immediately sees that the argument in the proof of Proposition 5.5 can be extended to show that for any insurance buyer $0 i$, the consumption plan $\left(c_{1}^{0 i C}, c_{2}^{0 i C}\right)=$ $\left(w^{0}+z_{1}^{0 i C}, w^{0}-d+z_{2}^{0 i C}\right)$ satisfies

$$
w^{0}-d<c_{2}^{0 i C}<c_{1}^{0 i C}<w^{0}
$$

for $m>1$ as well as for $m=1$. Analogues for the other parts of Proposition 5.5 are left to the reader.

From (7.18), one infers that any insurance buyer's net-trade plan in any Cournot rational-expectations equilibrium belongs to the compact set $[-d, 0] \times[0, d]$. By the same token, for any $\mathbf{e}_{-i} \in E_{-i}$, the aggregate $\frac{1}{m H} Z_{-i}^{C}\left(\mathbf{e}_{-i}\right)$ of the other insurance buyers' net claims on any one insurer belongs to the compact interval $\left[-\frac{d}{H}, \frac{d}{H}\right]$. As $m$ goes out of bounds, the ratio of the expected marginal utilities $\varphi\left(z_{1}^{0 i},\left\{z_{1}^{0 j C}, z_{2}^{0 j C}\right\}_{j \neq i}, \boldsymbol{\eta}_{-i}^{C}\right)$ and $\varphi\left(z_{2}^{0 i},\left\{z_{1}^{0 j C}, z_{2}^{0 j C}\right\}_{j \neq i}, \boldsymbol{\eta}_{-i}^{C}\right)$ in (7.16) converges to one, uniformly over all net-trade plans in the relevant range. ${ }^{10}$ Therefore one obtains the same convergence behaviour as for the case where $H$ goes out of bounds.

Proposition 7.5 Fix $H$ and let $\left\{\left(\mathbf{q}^{C m^{\prime}},\left\{z_{1}^{0 i C m^{\prime}}, z_{2}^{0 i C m^{\prime}}, \eta^{i C m^{\prime}}\right)\right\}_{i=1}^{m^{\prime}}\right\}$ be a sequence of Cournot rational-expectations equilibria with $\mathrm{m}^{\prime}$ insurance buyers and $m^{\prime} H$ insurers. For any $i$, let $\left(\mathbf{q}^{*}, z_{1}^{0 i *}, z_{2}^{0 i *}, \eta^{i *}\right)$ be a limit point of the sequence $\left\{\left(\sum_{\left\{\mathbf{e} \in E \mid s_{i}(\mathbf{e})=1\right\}} q^{C m^{\prime}}(\mathbf{e}), \sum_{\left\{\mathbf{e} \in E \mid s_{i}(\mathbf{e})=2\right\}} q^{C m^{\prime}}(\mathbf{e})\right),\left(z_{1}^{0 i C m^{\prime}}, z_{2}^{0 i C m^{\prime}}, \eta^{i C m^{\prime}}\right)\right\}$ as $m^{\prime}$ goes out of bounds. Then

$$
\mathbf{q}^{*}=\left(1-p_{2}\left(\eta^{*}\right), p_{2}\left(\eta^{*}\right)\right),
$$

and $\left(z_{1}^{0 i *}, z_{2}^{0 i *}, \eta^{i *}\right)$ maximizes $U\left(w^{0}+z_{1}^{0}, w_{2}^{0}-d+z_{2}^{0}, \eta\right)$ under the constraint

$$
\left(1-p_{2}\left(\eta\left(w^{0}+z_{1}^{0}, w_{2}^{0}-d+z_{2}^{0}\right)\right)\right) z_{1}^{0}+p_{2}\left(\eta\left(w^{0}+z_{1}^{0}, w_{2}^{0}-d+z_{2}^{0}\right)\right) z_{2}^{0} \leq 0 .
$$

\footnotetext{
${ }^{10}$ Indeed the law of large numbers implies that for $\left(\left(z_{1}^{0 i}, z_{2}^{0 i}\right),\left\{z_{1}^{0 j C}, z_{2}^{0 j C}\right\}_{j \neq i}\right) \in \Xi$, the expected marginal utilities $\varphi\left(z_{s}^{0 i},\left\{z_{1}^{0 j C}, z_{2}^{0 j C}\right\}_{j \neq i}, \boldsymbol{\eta}_{-i}^{C}\right)$ in (7.16) must all be close to $v^{\prime}\left(w^{1}\right)$
} 
The account of Cournot convergence given in Proposition 6.2 is thus quite general, applying to a sequence with $m^{\prime}$ insurance buyers with independent risks and $m^{\prime} H$ insurers, where $m^{\prime}$ goes out of bounds, just as it does to a sequence where the ratio $H$ of insurers to insurance buyers goes out of bounds.

In fact the only real difference between the specification with multiple insurance buyers and the specification with one insurance buyer seems to be that for $m>1$, the existence of a Cournot rational-expectations equilibrium cannot be taken for granted. The problem is well known from Roberts and Sonnenschein [33]. However, an argument from Roberts [34] can be adapted to give conditions ensuring that a Cournot rational-expectations equilibrium necessarily exists if the number of insurance buyers is sufficiently large.

Proposition 7.6 Suppose that, in addition to the assumptions made so far, the von Neumann-Morgenstern utility functions $u$ and $v$ are three times continuously differentiable. Assume further that the problem of maximizing $U\left(w^{0}+z_{1}^{0}, w_{2}^{0}-d+z_{2}^{0}, \eta\right)$ under the constraint (7.20) has a unique solution and that the second-order conditions for this solution hold with strict inequality. Then for any $H$ and any sufficiently large $m$, the economy with $m$ insurance buyers and $m H$ insurers has a Cournot rational-expectations equilibrium, which is moreover symmetric.

\section{Concluding Remarks}

To conclude the paper, I return to the discussion of contract theory and Walrasian general-equilibrium theory and the way the exclusivity problem is handled in the two approaches. I begin with a remark on perfect competition. Economic theory has two models of perfect competition, the Bertrand model of price competition between suppliers with constant marginal costs and the Walrasian model of organized markets with many agents where each agent is too small to have a significant impact on the rest of the economy. The latter is often referred to as involving agents too small to have a significant impact on market prices, but the analysis here suggests that this is not quite appropriate. When prices refer to personalized objects of trade such as the contingent claims on state referring to household 0's accident risk, there is no reason to expect equilibrium prices to be insensitive to the quantity choices of the agent concerned, but this does not mean that this agent has any power over anybody's well being. 
The two notions of perfect competition have very different strategic foundations. Whereas in the Walrasian setting, perfectly competitive outcomes arise because no one individual has any power, the Bertrand model gives rise to perfectly competitive outcomes because competing powers neutralize each other. The mutual neutralization of power results from each agent's fear that his clients will leave him for his competitor. If one insurer attempted to raise his insurance premium, his clients would just go to another insurer. This presumes that another insurer is actually available, i.e., that there is always a "reserve supply" of insurance that is not actually used, but would be available the moment one of the "incumbent insurers" tried to exploit his clients.

The existence of such a "reserve supply" of insurance gives the exclusivity problem its bite. As discussed in the introduction, with insurance contracts involving deductibles or coinsurance, i.e., $c_{2}^{0}<c_{1}^{0}$ in terms of the analysis here, the insurance buyer has an incentive to secretly conclude an additional insurance contract with an additional insurer if such an additional insurer is available. In the Bertrand model, additional insurers are necessarily available because their "reserve supplies" of insurance are needed to discipline the incumbents.

In the Walrasian setting, this problem does not arise, at least, if the insurance buyer takes account of the relation between his quantity choices and market-clearing prices. As the insurance buyer is trading with the market, he is actually trading with everybody, and there is nobody left as a potential partner for secret side-contracting. Exclusivity is not an issue because "the market" observes the insurance buyer's overall position, and the market-clearing price communicates this information to insurers who draw the appropriate inference about the insurance buyer's effort incentives and choose their own positions accordingly.

One may object that this analysis exaggerates the information transmission role of market prices. Is it really reasonable to assume that "the market" observes a given trader's total net-trade vector as sharply as the appearance of this net-trade vector in the market-clearing conditions would seem to suggest? Or would it be more reasonable to follow the literature on rational-expectations equilibrium with asymmetric information, e.g., Grossman [12], and inject a little bit of "noise" into the system?

The question of what happens to insurance subject to moral hazard in such a "noisy" setting poses an entirely new research problem. For the moment, I merely note that the traditional "noiseless" market-clearing conditions (4.6) and (4.7) lead to the conclusion that in the Cournot approach the Walrasian system of organizationed markets solves the exclusivity prob- 
lem associated with nonlinear incentive contracting by the simple device of having "the market" observe each agent's total net-trade vector and transmitting this information through market prices.

\section{A Appendix: Proofs}

The proofs of Lemma 2.1 and Proposition 3.1 are standard and are omitted here. The reader is referred to Hellwig [18].

The proof of Proposition 3.2 is based on the following lemma.

Lemma A.1 For any $H$, let $\Phi^{H}$ be the set of pairs $\left(c_{1}^{0 H}, c_{2}^{0 H}\right)$ satisfying $w^{0}-d \leq c_{2}^{0 H} \leq c_{1}^{0 H} \leq w^{0}$ as well as

$$
V\left(w^{1}+\frac{1}{H}\left(w^{0}-c_{1}^{0 H}\right), w^{1}+\frac{1}{H}\left(w^{0}-d-c_{2}^{0 H}\right), \eta\left(c_{1}^{0 H}, c_{2}^{0 H}\right)\right) \geq v\left(w^{1}\right) .
$$

As $H$ goes out of bounds, the sets $\Phi^{H}$ converge in the Hausdorff topology to the set $\Phi^{*}$ of pairs $\left(c_{1}^{0}, c_{2}^{0}\right)$ satisfying $w^{0}-d \leq c_{2}^{0} \leq c_{1}^{0} \leq w^{0}$ as well as (3.9).

Proof. I first note that any sequence $\left\{\left(c_{1}^{0 H}, c_{2}^{0 H}\right)\right\}_{H=1}^{\infty}$ of elements of $\Phi^{H}, H=1,2, \ldots$, lies in $\left[0, w^{0}\right]^{2}$ and must have a convergent subsequence. Since $v($.$) is a concave function, for any H$, the validity of (A.1) implies that $\left(c_{1}^{0 H}, c_{2}^{0 H}\right) \in \Phi^{H}$ satisfies (3.9). Since $p_{2}($.$) and \eta(.,$.$) are continuous, it$ follows that any limit point $\left(c_{1}^{0}, c_{2}^{0}\right)$ of a sequence $\left\{\left(c_{1}^{0 H}, c_{2}^{0 H}\right)\right\}_{H=1}^{\infty}$ of elements of $\Phi^{H}, H=1,2, \ldots$, must satisfy (3.9) as well. Trivially, such a limit point also satisfies $\left(c_{1}^{0}, c_{2}^{0}\right) \in\left[0, w^{0}\right]^{2}$ and $c_{1}^{0} \geq c_{2}^{0}$, and hence is an element of $\Phi^{*}$.

To complete the argument, I also show that for any point $\left(c_{1}^{0}, c_{2}^{0}\right) \in \Phi^{*}$ there exists a sequence $\left\{\left(c_{1}^{0 H}, c_{2}^{0 H}\right)\right\}_{H=1}^{\infty}$ of elements of $\Phi^{H}, H=1,2, \ldots$, that converges to $\left(c_{1}^{0}, c_{2}^{0}\right)$. If $w^{0}-d=c_{2}^{0} \leq c_{1}^{0} \leq w^{0}$, then trivially the pair $\left(c_{1}^{0}, c_{2}^{0}\right)$ itself belongs to $\Phi^{H}$ for all $H$, and there is nothing left to prove.

Suppose therefore that $w^{0}-d<c_{2}^{0} \leq c_{1}^{0} \leq w^{0}$ and note that, by (3.9), $w^{0}-d<c_{2}^{0}$ implies $p_{2}\left(\eta\left(c_{1}^{0}, c_{2}^{0}\right)\right)<1$. I claim that for any sufficiently large integer $n$, one may define $\left(c_{1}^{0 n}, c_{2}^{0 n}\right)$ so that $w^{0}-d<c_{2}^{0 n} \leq c_{1}^{0 n}=c_{1}^{0}-\frac{1}{n} \leq w^{0}$ and

$$
\eta\left(c_{1}^{0 n}, c_{2}^{0 n}\right)=\eta\left(c_{1}^{0}, c_{2}^{0}\right) .
$$

To see that this can be done, observe first that if $w^{0}-d<c_{2}^{0} \leq c_{1}^{0}$, then for any sufficiently large integer $n, c_{1}^{0}-\frac{1}{n}>w^{0}-d$. If $\eta\left(c_{1}^{0}, c_{2}^{0}\right)=0$, then by Lemma 2.1, one also has $\eta\left(c_{1}^{0}-\frac{1}{n}, c_{2}^{0 n}\right)=0$ whenever $c_{2}^{0 n} \geq c_{2}^{0}$, so the claim is verified with $c_{1}^{0 n}=c_{1}^{0}-\frac{1}{n}$ and $c_{2}^{0 n}=\min \left(c_{2}^{0}, c_{1}^{0 n}\right)$. If instead $\eta\left(c_{1}^{0}, c_{2}^{0}\right)>0$, 
then by Lemma 2.1, one has $c_{2}^{0}<c_{1}^{0}$, and by the implicit function theorem, there exist an open neighbourhood of $c_{1}^{0}$ and an increasing, continuously differentiable function $\gamma($.$) , such that for any c_{1}^{0 n}$, (A.2) is satisfied if and only if $c_{2}^{0 n}=\gamma\left(c_{1}^{0 n}\right)$; in particular, $c_{2}^{0}=\gamma\left(c_{1}^{0}\right)$. For $n$ sufficiently large, $c_{1}^{0 n}=c_{1}^{0}-\frac{1}{n}$ may be taken to belong to the given neighbourhood of $c_{1}^{0}$, and with $c_{2}^{0 n}=\gamma\left(c_{1}^{0 n}\right)$ satisfies $(A .2)$; moreover since $\gamma($.$) is continuous,$ one may suppose that $w^{0}-d<c_{2}^{0 n}<c_{1}^{0 n}$ for any sufficiently large $n$. Thus in the case $\eta\left(c_{1}^{0}, c_{2}^{0}\right)>0$ as well as the case $\eta\left(c_{1}^{0}, c_{2}^{0}\right)=0$, if $n$ is sufficiently large, there exists a pair $\left(c_{1}^{0 n}, c_{2}^{0 n}\right)$ that satisfies (A.2) as well as $w^{0}-d<c_{2}^{0 n} \leq c_{1}^{0 n}=c_{1}^{0}-\frac{1}{n} \leq w^{0}$. In either case, one also has $c_{2}^{0 n} \leq c_{2}^{0}$.

For any $H$ consider the expected utility that households $1,2, \ldots, H$ associate with the feasible equal-treatment allocation implied by the pair $\left(c_{1}^{0 n}, c_{2}^{0 n}\right)$ so defined. By the concavity of $v($.$) , one obtains$

$$
\begin{gathered}
V\left(w^{1}+\frac{1}{H}\left(w^{0}-c_{1}^{0 n}\right), w^{1}+\frac{1}{H}\left(w^{0}-d-c_{2}^{0 n}\right), \eta\right) \\
\geq v\left(w^{1}\right)+\left(1-p_{2}(\eta)\right) v^{\prime}\left(w^{1}+\frac{1}{H}\left(w^{0}-c_{1}^{0 n}\right)\right) \frac{1}{H}\left(w^{0}-c_{1}^{0 n}\right) \\
+p_{2}(\eta) v^{\prime}\left(w^{1}+\frac{1}{H}\left(w^{0}-d-c_{2}^{0 n}\right)\right) \frac{1}{H}\left(w^{0}-d-c_{2}^{0 n}\right),
\end{gathered}
$$

where $\eta$ denotes the common value of $\eta\left(c_{1}^{0 n}, c_{2}^{0 n}\right)$ and $\eta\left(c_{1}^{0}, c_{2}^{0}\right)$. By a rearrangement of terms on the right-hand side, (A.3) becomes

$$
\begin{gathered}
V\left(w^{1}+\frac{1}{H}\left(w^{0}-c_{1}^{0 n}\right), w^{1}+\frac{1}{H}\left(w^{0}-d-c_{2}^{0 n}\right), \eta\right) \\
\geq v\left(w^{1}\right)+v^{\prime}\left(w^{1}+\frac{1}{H}\left(w^{0}-c_{1}^{0 n}\right)\right) \frac{1}{H}\left[w^{0}-\left(1-p_{2}(\eta)\right)\left(c_{1}^{0}-\frac{1}{n}\right)-p_{2}(\eta)\left(c_{2}^{0}+d\right)\right] \\
+p_{2}(\eta)\left[v^{\prime}\left(w^{1}+\frac{1}{H}\left(w^{0}-d-c_{2}^{0 n}\right)\right)-v^{\prime}\left(w^{1}+\frac{1}{H}\left(w^{0}-c_{1}^{0 n}\right)\right)\right] \frac{1}{H}\left(w^{0}-d-c_{2}^{0 n}\right) .
\end{gathered}
$$

By (3.9), the second term on the right-hand side is nonnegative and can be dropped. Moreover, if one uses the mean value theorem to simplify the third term on the right-hand side, one obtains

$$
\begin{gathered}
V\left(w^{1}+\frac{1}{H}\left(w^{0}-c_{1}^{0 n}\right), w^{1}+\frac{1}{H}\left(w^{0}-d-c_{2}^{0 n}\right), \eta\right) \\
\geq v\left(w^{1}\right)+v^{\prime}\left(w^{1}+\frac{1}{H}\left(w^{0}-c_{1}^{0 n}\right)\right) \frac{1}{H} \frac{1-p_{2}(\eta)}{n} \\
-p_{2}(\eta) v^{\prime \prime}\left(w^{1}+\theta^{H}\right) \frac{1}{H}\left(c_{1}^{0 n}-c_{2}^{0 n}-d\right) \frac{1}{H}\left(w^{0}-d-c_{2}^{0 n}\right),
\end{gathered}
$$

where $\theta^{H}$ is some element of the interval $\left[\frac{1}{H}\left(w^{0}-d-c_{2}^{0 n}\right), \frac{1}{H}\left(w^{0}-c_{1}^{0 n}\right)\right]$. Now with $c_{1}^{0 n}=c_{1}^{0}-\frac{1}{n} \geq c_{2}^{0 n} \geq w^{0}-d$, the second term on the right-hand side is 
bounded below by $v^{\prime}\left(w^{1}+\frac{1}{H} d\right) \frac{1-p_{2}(\eta)}{H n}>0$. As for the third term on the righthand side, I note that $c_{1}^{0 n}-c_{2}^{0 n}-d \geq-d$, and, trivially, $w^{0}-d-c_{2}^{0 n} \leq w^{0}$, so this term is bounded below by $p_{2}(\eta) v^{\prime \prime}\left(w^{1}+\theta^{H}\right) d w^{0} / H^{2}$. It follows that

$$
\begin{gathered}
V\left(w^{1}+\frac{1}{H}\left(w^{0}-c_{1}^{0 n}\right), w^{1}+\frac{1}{H}\left(w^{0}-d-c_{2}^{0 n}\right), \eta\right) \\
\geq v\left(w^{1}\right)+\frac{1}{H}\left[v^{\prime}\left(w^{1}+\frac{1}{H} d\right) \frac{1-p_{2}(\eta)}{n}+p_{2}(\eta) v^{\prime \prime}\left(w^{1}+\theta^{H}\right) d \frac{w^{0}}{H}\right] .
\end{gathered}
$$

Now it is clear that for the given $n$, there exists $H^{n}$ such that for $H \geq H^{n}$, one has

$$
v^{\prime}\left(w^{1}+\frac{1}{H} d\right) \frac{1-p_{2}(\eta)}{n}+p_{2}(\eta) v^{\prime \prime}\left(w^{1}+\theta^{H}\right) d \frac{w^{0}}{H} \geq 0,
$$

and therefore

$$
V\left(w^{1}+\frac{1}{H}\left(w^{0}-c_{1}^{0 n}\right), w^{1}+\frac{1}{H}\left(w^{0}-d-c_{2}^{0 n}\right), \eta\right) \geq v\left(w^{1}\right) .
$$

Upon setting $\left(c_{1}^{0 H}, c_{2}^{0 H}\right)=\left(c_{1}^{0 n}, c_{2}^{0 n}\right)$ if $H^{n} \leq H<H^{n+1}$, one thus obtains a sequence $\left\{\left(c_{1}^{0 H}, c_{2}^{0 H}\right)\right\}$ of elements of $\Phi^{H}, H=1,2, \ldots$ that converges to $\left(c_{1}^{0}, c_{2}^{0}\right)$. This completes the proof that the sets $\Phi^{H}, H=1,2, \ldots$, converge to $\Phi^{*}$.

Proof of Proposition 3.2. From Lemma 2.1 and the feasibility constraint (2.6), for any $H$, the allocation $\left(\left\{c_{1}^{h H}, c_{2}^{h H}\right\}_{h=0}^{H}, \eta^{H}\right)$ is an equaltreatment second-best allocation with common utility bound $\bar{v}^{h}=v\left(w^{1}\right)$ if and only if it is feasible and $\left(c_{1}^{0 H}, c_{2}^{0 H}\right)$ solves the problem

$$
\max _{\left(c_{1}^{0 H}, c_{2}^{0 H}\right)} U\left(c_{1}^{0 H}, c_{2}^{0 H}, \eta\left(c_{1}^{0 H}, c_{2}^{0 H}\right)\right)
$$

subject to (A.1). By Proposition 3.1, the solutions to this maximization problem satisfy $w^{0}-d \leq c_{2}^{0 H} \leq c_{1}^{0 H} \leq w^{0}$, so there is no loss of generality in supposing that the maximization in (A.4) is restricted to the set $\Phi^{H}$ of pairs satisfying these inequalities as well as (A.1).

As discussed by Shavell [37], the solutions $\left(c_{1}^{0}, c_{2}^{0}\right)$ to the problem of maximizing (3.8) subject to (3.9) must also satisfy $w^{0}-d \leq c_{2}^{0} \leq c_{1}^{0} \leq w^{0}$, so there is also no loss of generality in supposing that the maximization in (3.8) is restricted to the set $\Phi^{*}$ of pairs that satisfy these inequalities as well as (3.9).

Lemma 2.1 implies that the sets $\Phi^{H}, H=1,2, \ldots$, and $\Phi^{*}$ are closed subsets of the compact set $\left[0, w^{0}\right]^{2}$ and are themselves compact. By the 
maximum theorem (see, e.g., Hildenbrand [20], pp. 29f.), it follows that if the sets $\Phi^{H}$ converge to $\Phi^{*}$ in the Hausdorff topology, then any limit point $\left(c_{1}^{0}, c_{2}^{0}\right)$ of the sequence $\left\{\left(c_{1}^{0 H}, c_{2}^{0 H}\right)\right\}_{H=1}^{\infty}$ is a solution to the problem of maximizing (3.8) over the set $\Phi^{*}$ and hence a solution to the problem of maximizing (3.8) subject to (3.9).

Proof of Lemma 4.1. Using the budget constraint $q_{1} c_{1}^{1}+q_{2} c_{2}^{2}=w^{1}$, one easily finds that for any strictly positive $\mathbf{q} \in \boldsymbol{\Sigma}$, a pair $\left(c_{1}^{0}, c_{2}^{0}\right) \in \Re_{+}^{2}$ satisfies (4.2) and (4.3), if and only if

$$
c_{2}^{0}=w^{0}-d+\frac{q_{1}}{q_{2}}\left(w^{0}-c_{1}^{0}\right)
$$

and

$$
c_{1}^{0}+H c_{1}^{1}\left(\mathbf{q}, \eta\left(c_{1}^{0}, w^{0}-d+\frac{q_{1}}{q_{2}}\left(w^{0}-c_{1}^{0}\right)\right)\right)=w^{0}+H w^{1} .
$$

The lemma is thus equivalent to the claim that for any $\mathbf{q}>>0$, there exists at most one $c_{1}^{0}$ that satisfies (A.6).

Given the budget constraint $q_{1} c_{1}^{1}+q_{2} c_{2}^{2}=w^{1}$ the function $c_{1}^{1}(.,$.$) must$ satisfy the first-order condition

$$
\frac{1-p_{2}(\eta)}{p_{2}(\eta)} \frac{v^{\prime}\left(c_{1}^{1}\right)}{v^{\prime}\left(\frac{w^{1}-q_{1} c_{1}^{1}}{q_{2}}\right)}=\frac{q_{1}}{q_{2}} .
$$

Since $\left(1-p_{2}(\eta)\right) / p_{2}(\eta)$ is increasing in $\eta$ and $v^{\prime}\left(c_{1}^{1}\right) / v^{\prime}\left(\frac{w^{1}-q_{1} c_{1}^{1}}{q_{2}}\right)$ is decreasing in $c_{1}^{1}$, (A.7) implies that $c_{1}^{1}(\mathbf{q}, \eta)$ is increasing in $\eta$. By Lemma 2.1, it follows that $c_{1}^{1}\left(\mathbf{q}, \eta\left(c_{1}^{0}, w^{0}-d+\frac{q_{1}}{q_{2}}\left(w^{0}-c_{1}^{0}\right)\right)\right)$ is nondecreasing in $c_{1}^{0}$ and hence, that the left-hand side of (A.6) is increasing in $c_{1}^{0}$. Therefore there cannot be more than one value of $c_{1}^{0}$ for which (A.6) is satisfied.

Proof of Lemma 4.2. By the definition of $\Gamma$, for $\left(c_{1}^{0}, c_{2}^{0}\right) \in \Gamma$, there exists $\mathbf{q} \in Q$ such that $\left(c_{1}^{0}, c_{2}^{0}\right)=\gamma(\mathbf{q})$. By the definition of $\boldsymbol{\gamma}($.$) , for any price$ vector $\mathbf{q}$ satisfying $\left(c_{1}^{0}, c_{2}^{0}\right)=\gamma(\mathbf{q})$, the consumption plan $\left(c_{1}^{0}, c_{2}^{0}\right)$ satisfies the market-clearing conditions (4.2) and (4.3). By the definitions of $\eta^{*}($.$) and$ $\left(C_{1}^{1}(),. C_{2}^{1}().\right)$, for $s=1,2$, one also has:

$$
c_{s}^{1}\left(\mathbf{q}, \eta\left(c_{1}^{0}, c_{2}^{0}\right)\right)=c_{s}^{1}(\mathbf{q}, \eta(\gamma(\mathbf{q})))=c_{s}^{1}\left(\mathbf{q}, \eta^{*}(\mathbf{q})\right)=C_{s}^{1}(\mathbf{q}) .
$$

Upon substituting for $c_{s}^{1}\left(\mathbf{q}, \eta\left(c_{1}^{0}, c_{2}^{0}\right)\right)=C_{s}^{1}(\mathbf{q})$ in (4.2) and (4.3), one finds that for the given $\left(c_{1}^{0}, c_{2}^{0}\right) \in \Gamma$, any price vector $\mathbf{q}$ satisfying $\left(c_{1}^{0}, c_{2}^{0}\right)=\gamma(\mathbf{q})$ must also satisfy (4.6) and (4.7). 
I next prove that for any $\left(c_{1}^{0}, c_{2}^{0}\right) \in \Gamma$, there is no more than one $\mathbf{q} \in Q$ for which (4.6) and (4.7) hold. Since any price vector q satisfying $\left(c_{1}^{0}, c_{2}^{0}\right)=\gamma(\mathbf{q})$ must also satisfy (4.6) and (4.7), this automatically implies that there is no more than one $\mathbf{q} \in Q$ for which $\left(c_{1}^{0}, c_{2}^{0}\right)=\gamma(\mathbf{q})$ and hence, that the function $\gamma($.$) is invertible.$

I give separate arguments for the cases $\left(c_{1}^{0}, c_{2}^{0}\right)=\left(w^{0}, w^{0}-d\right)$ and $\left(c_{1}^{0}, c_{2}^{0}\right) \neq\left(w^{0}, w^{0}-d\right)$. If $\left(c_{1}^{0}, c_{2}^{0}\right) \neq\left(w^{0}, w^{0}-d\right)$, then for any $\mathbf{q}$ validating (4.6) and (4.7), one has $\left(C_{1}^{1}(\mathbf{q}), C_{2}^{1}(\mathbf{q})\right) \neq\left(w^{1}, w^{1}\right)$, so, from the budget constraint for households $1,2, \ldots, H$, one obtains

$$
\frac{q_{1}}{q_{2}}=-\frac{w^{1}-C_{2}^{1}(\mathbf{q})}{w^{1}-C_{1}^{1}(\mathbf{q})}
$$

From (4.6) and (4.7), this in turn yields

$$
\frac{q_{1}}{q_{2}}=-\frac{c_{2}^{0}-\left(w^{0}-d\right)}{c_{1}^{0}-w^{0}},
$$

which in conjunction with $q_{1}=1-q_{2}$ implies that for $\left(c_{1}^{0}, c_{2}^{0}\right) \in \Gamma$ unequal to $\left(w^{0}, w^{0}-d\right)$, the price vector $\mathbf{q}$ that validates (4.6) and (4.7) is well defined and unique.

Alternatively, if $\left(c_{1}^{0}, c_{2}^{0}\right)=\left(w^{0}, w^{0}-d\right)$, then for any $\mathbf{q}$ validating (4.6) and (4.7), one has $\left(C_{1}^{1}(\mathbf{q}), C_{2}^{1}(\mathbf{q})\right)=\left(w^{1}, w^{1}\right)$, so from the first-order conditions for $\left(C_{1}^{1}(\mathbf{q}), C_{2}^{1}(\mathbf{q})\right)=\left(c_{1}^{1}\left(\mathbf{q}, \eta\left(w^{0}, w^{0}-d\right)\right), c_{2}^{1}\left(\mathbf{q}, \eta\left(w^{0}, w^{0}-d\right)\right)\right)$, one obtains

$$
\frac{q_{1}}{q_{2}}=\frac{1-p_{2}\left(\eta\left(w^{0}, w^{0}-d\right)\right)}{p_{2}\left(\eta\left(w^{0}, w^{0}-d\right)\right)}
$$

which in conjunction with $q_{1}=1-q_{2}$ shows that for $\left(c_{1}^{0}, c_{2}^{0}\right) \in \Gamma$ equal to $\left(w^{0}, w^{0}-d\right)$, the price vector $\mathbf{q}$ that validates (4.6) and (4.7) is also unique.

Given the definitions of the functions $\mathbf{q}^{*}($.$) and \eta^{*}($.$) , for any \left(c_{1}^{0}, c_{2}^{0}\right) \in \Gamma$, we have

$$
\eta^{*}\left(\mathbf{q}^{*}\left(c_{1}^{0}, c_{2}^{0}\right)\right)=\eta\left(\gamma\left(\mathbf{q}^{*}\left(c_{1}^{0}, c_{2}^{0}\right)\right)\right)=\eta\left(c_{1}^{0}, c_{2}^{0}\right),
$$

as claimed in (4.8).

Proof of Proposition 4.3. I first show that any pair $\left(c_{1}^{0}, c_{2}^{0}\right) \in$ $\bar{\Gamma}$ satisfies (4.11). For $\left(c_{1}^{0}, c_{2}^{0}\right) \in \bar{\Gamma} \backslash \Gamma$, one has $1-p_{2}\left(\eta\left(c_{1}^{0}, c_{2}^{0}\right)\right)=0$ and $c_{2}^{0}=w^{0}-d$, so (4.11) is trivially satisfied. For $\left(c_{1}^{0}, c_{2}^{0}\right) \in \Gamma$, use Lemma 4.2 to define $\mathbf{q}=\mathbf{q}^{*}\left(c_{1}^{0}, c_{2}^{0}\right)$ and $\eta=\eta^{*}(\mathbf{q})=\eta\left(c_{1}^{0}, c_{2}^{0}\right)$. Then $\left(c_{1}^{0}, c_{2}^{0}\right)$ and $\mathbf{q}=\left(q_{1}, q_{2}\right)$ satisfy (4.6) and (4.7) and hence, by the argument given in the proof of Lemma 4.2, the budget constraint

$$
q_{1}\left(c_{1}^{0}-w^{0}\right)+q_{2}\left(c_{2}^{0}-\left(w^{0}-d\right)\right)=0 .
$$


By the first-order condition for $\left(C_{1}^{1}(\mathbf{q}), C_{2}^{1}(\mathbf{q})\right)$, one also has

$$
\frac{q_{1}}{q_{2}}=\frac{\left(1-p_{2}(\eta)\right)}{p_{2}(\eta)} \frac{v^{\prime}\left(C_{1}^{1}(\mathbf{q})\right)}{v^{\prime}\left(C_{2}^{1}(\mathbf{q})\right)}
$$

Upon combining (A.8) and (A.9), one obtains

$$
\left(1-p_{2}(\eta)\right) v^{\prime}\left(C_{1}^{1}(\mathbf{q})\right)\left(c_{1}^{0}-w^{0}\right)+p_{2}(\eta) v^{\prime}\left(C_{2}^{1}(\mathbf{q})\right)\left(c_{2}^{0}-\left(w^{0}-d\right)\right),
$$

so (4.11) follows if one uses (4.6) and (4.7) to substitute for $\left(C_{1}^{1}(\mathbf{q}), C_{2}^{1}(\mathbf{q})\right)$.

I next show that any pair $\left(c_{1}^{0}, c_{2}^{0}\right)$ satisfying (4.11) must belong to $\bar{\Gamma}$. Given $\left(c_{1}^{0}, c_{2}^{0}\right)$ satisfying (4.11), define $\mathbf{q}=\left(q_{1}, q_{2}\right)$ by setting $q_{1}=1-q_{2}$ and

$$
\frac{q_{1}}{q_{2}}=\frac{\left(1-p_{2}(\eta)\right)}{p_{2}(\eta)} \frac{v^{\prime}\left(c_{1}^{1}\right)}{v^{\prime}\left(c_{2}^{1}\right)}
$$

where $\eta=\eta\left(c_{1}^{0}, c_{2}^{0}\right)$, and $c_{1}^{1}=w^{1}+\frac{1}{H}\left(w^{0}-c_{1}^{0}\right), c_{2}^{1}=w^{1}+\frac{1}{H}\left(w^{0}-d-c_{2}^{0}\right)$. If $q_{1}=0$, one must have $p_{2}(\eta)=1$, in which case (4.11) implies $w^{0}-d-c_{2}^{0}=0$. By the strict monotonicity of $p_{2}(),. p_{2}(\eta)=1$ also implies that $\eta=0$ and hence, $\left(c_{1}^{0}, c_{2}^{0}\right) \in \bar{\Gamma}$. Alternatively if $q_{1}>0$, then from (4.11) one infers that at the price vector $\left(q_{1}, q_{2}\right),\left(c_{1}^{0}, c_{2}^{0}\right)$ also satisfies the budget constraint (A.8). By the definition of $c_{1}^{1}$ and $c_{2}^{1}$, it follows that the pair $\left(c_{1}^{1}, c_{2}^{1}\right)$ satisfies the budget constraint $q_{1} c_{1}^{1}+q_{2} c_{2}^{1}=w^{1}$. Since (A.10) is just the first-order condition for the maximization of $V\left(c_{1}^{1}, c_{2}^{1}, \eta\right)$ under the given budget constraint, it follows that

$$
\left(c_{1}^{1}, c_{2}^{1}\right)=\left(c_{1}^{1}(\mathbf{q}, \eta), c_{2}^{1}(\mathbf{q}, \eta)\right)
$$

and hence, that $\left(c_{1}^{0}, c_{2}^{0}\right)$ satisfies (4.2) and (4.3) for the specified price vector $\mathbf{q}>>\mathbf{0}$. Thus $\left(c_{1}^{0}, c_{2}^{0}\right)=\boldsymbol{\gamma}(\mathbf{q})$, which proves that $\left(c_{1}^{0}, c_{2}^{0}\right)$ belongs the $\Gamma$, the range of $\gamma($.$) .$

Proof of Lemma 5.3. If $\left(\mathbf{q}^{*},\left\{c_{1}^{h *}, c_{2}^{h *}\right\}_{h=0}^{H}, \eta^{*}\right)$ is a Walrasian or a Cournot rational-expectations equilibrium, condition (iii) in Definition 5.1 or 5.2 implies that

$$
\left(c_{1}^{h *}, c_{2}^{h *}\right)=\left(C_{1}\left(\mathbf{q}^{*}\right), C_{2}\left(\mathbf{q}^{*}\right)\right)
$$

for $h=1,2, \ldots, H$. By condition (i), it follows that

$$
\left(c_{1}^{0 *}, c_{2}^{0 *}\right)=\left(w^{0}, w^{0}-d\right)-\frac{1}{H}\left(C_{1}\left(\mathbf{q}^{*}\right)-w^{1}, C_{2}\left(\mathbf{q}^{*}\right)-w^{1}\right),
$$

so $\left(c_{1}^{0 *}, c_{2}^{0 *}\right)$ satisfies $(4.6)$ and (4.7) for the price vector $\mathbf{q}^{*}$. Therefore $\left(c_{1}^{0 *}, c_{2}^{0 *}\right) \in$ $\bar{\Gamma}$ and $\mathbf{q}^{*}=\mathbf{q}^{*}\left(c_{1}^{0 *}, c_{2}^{0 *}\right)$. By Lemma 4.2 , it follows that $\eta^{*}\left(\mathbf{q}^{*}\right)=\eta\left(c_{1}^{0 *}, c_{2}^{0 *}\right)$. By condition (ii) in Definition 5.1 or 5.2 , we also have $\eta^{*}=\eta\left(c_{1}^{0 *}, c_{2}^{0 *}\right)$. 
The proof of Proposition 5.4 is standard and is omitted here. The reader is referred to Hellwig [18].

Proof of Proposition 5.5. If $\left(\mathbf{q}^{C},\left\{c_{1}^{h C}, c_{2}^{h C}\right\}_{h=0}^{H}, \eta^{C}\right)$ is a Cournot rational-expectations equilibrium, condition (iii) in Definition 5.2 implies the equal-treatment property $\left(c_{1}^{h C}, c_{2}^{h C}\right)=\left(c_{1}^{1 C}, c_{2}^{1 C}\right)$ for $h=1, \ldots, H$. By the feasibility condition (i), it follows that

$$
\left(c_{1}^{1 C}, c_{2}^{1 C}\right)=\left(w^{1}, w^{1}\right)+\frac{1}{H}\left(w^{0}-c_{1}^{0 C}, w^{0}-d-c_{2}^{0 C}\right) .
$$

Condition (ii) of Definition 5.2 and Proposition 4.3 imply that the triple $\left(c_{1}^{0 C}, c_{2}^{0 C}, \eta^{C}\right)$ satisfies the first-order conditions

$$
\begin{gathered}
\left(1-p_{2}\left(\eta^{C}\right)\right) u^{\prime}\left(c_{1}^{0 C}\right)-\frac{\lambda}{H}\left(1-p_{2}\left(\eta^{C}\right)\right) v^{\prime}\left(c_{1}^{1 C}\right)+\frac{\lambda}{H^{2}}\left(1-p_{2}\left(\eta^{C}\right)\right) v^{\prime \prime}\left(c_{1}^{1 C}\right)\left(c_{1}^{0 C}-w^{0}\right) \\
-\lambda\left(-p_{2}^{\prime}\left(\eta^{C}\right)\right)\left[v^{\prime}\left(c_{1}^{1 C}\right)\left(c_{1}^{0 C}-w^{0}\right)-v^{\prime}\left(c_{2}^{1 C}\right)\left(c_{2}^{0 C}-\left(w^{0}-d\right)\right)\right] \frac{\partial \eta}{\partial c_{1}^{0}}=0 \\
p_{2}\left(\eta^{C}\right) u^{\prime}\left(c_{2}^{0 C}\right)-\frac{\lambda}{H} p_{2}\left(\eta^{C}\right) v^{\prime}\left(c_{2}^{1 C}\right)+\frac{\lambda}{H^{2}} p_{2}\left(\eta^{C}\right) v^{\prime \prime}\left(c_{2}^{1 C}\right)\left(c_{2}^{0 C}-\left(w^{0}-d\right)\right) \\
-\lambda\left(-p_{2}^{\prime}\left(\eta^{C}\right)\right)\left[v^{\prime}\left(c_{1}^{1 C}\right)\left(c_{1}^{0 C}-w^{0}\right)-v^{\prime}\left(c_{2}^{1 C}\right)\left(c_{2}^{0 C}-\left(w^{0}-d\right)\right)\right] \frac{\partial \eta}{\partial c_{2}^{0}}=0,
\end{gathered}
$$

and $\eta^{C}=\eta\left(c_{1}^{0 C}, c_{2}^{0 C}\right)$ where $\left(c_{1}^{1 C}, c_{2}^{1 C}\right)$ satisfies (A.11).

I claim that $p_{2}\left(\eta^{C}\right)<1$. For suppose that $p_{2}\left(\eta^{C}\right)=1$. Then (4.11) implies $c_{2}^{0 C}=w^{0}-d$. Then also (A.12) implies $c_{1}^{0 C}=w^{0}$. By Lemma 2.1, it follows that $\eta^{C}=\eta\left(c_{1}^{0 C}, c_{2}^{0 C}\right)>0$, hence $p_{2}\left(\eta^{C}\right)<1$. The assumption that $p_{2}\left(\eta^{C}\right)=1$ thus leads to a contradiction and must be false.

Next I claim that $c_{1}^{0 C}<w^{0}$. For suppose that $c_{1}^{0 C} \geq w^{0}$. Then (4.11) implies $c_{2}^{0 C} \leq w^{0}-d$. Then Lemma 2.1 implies $\frac{\partial \eta}{\partial c_{1}^{0}}>0$ and $\frac{\partial \eta}{\partial c_{2}^{0}}<0$. The first-order conditions (A.12) and (A.13) yield

$$
\left(1-p_{2}\left(\eta^{C}\right)\right) u^{\prime}\left(c_{1}^{0 C}\right) \geq \frac{\lambda}{H}\left(1-p_{2}\left(\eta^{C}\right)\right) v^{\prime}\left(c_{1}^{1 C}\right)
$$

and

$$
p_{2}\left(\eta^{C}\right) u^{\prime}\left(c_{2}^{0 C}\right) \leq \frac{\lambda}{H} p_{2}\left(\eta^{C}\right) v^{\prime}\left(c_{2}^{1 C}\right),
$$


hence

$$
1>\frac{u^{\prime}\left(w^{0}\right)}{u^{\prime}\left(w^{0}-d\right)} \geq \frac{u^{\prime}\left(c_{1}^{0 C}\right)}{u^{\prime}\left(c_{2}^{0 C}\right)} \geq \frac{v^{\prime}\left(c_{1}^{1 C}\right)}{v^{\prime}\left(c_{2}^{1 C}\right)} .
$$

By the concavitiy of $v($.$) , it follows that c_{1}^{1 C}>c_{2}^{1 C}$. By (A.11) therefore, $w^{0}-c_{1}^{0 C}>w^{0}-d-c_{2}^{0 C}$, which is impossible if $c_{1}^{0 C} \geq w^{0}$ and $c_{2}^{0 C} \leq w^{0}-d$. The assumption that $c_{1}^{0 C} \geq w^{0}$ thus leads to a contradiction and must be false.

By (4.11), $c_{1}^{0 C}<w^{0}$ also implies $c_{2}^{0 C}>w^{0}-d$. Therefore (A.12) and (A.13) imply that

$$
\left(1-p_{2}\left(\eta^{C}\right)\right) u^{\prime}\left(c_{1}^{0 C}\right)<\frac{\lambda}{H}\left(1-p_{2}\left(\eta^{C}\right)\right) v^{\prime}\left(c_{1}^{1 C}\right)
$$

and

$$
p_{2}\left(\eta^{C}\right) u^{\prime}\left(c_{2}^{0 C}\right)>\frac{\lambda}{H} p_{2}\left(\eta^{C}\right) v^{\prime}\left(c_{2}^{1 C}\right),
$$

hence

$$
\frac{u^{\prime}\left(c_{1}^{0 C}\right)}{u^{\prime}\left(c_{2}^{0 C}\right)}<\frac{v^{\prime}\left(c_{1}^{1 C}\right)}{v^{\prime}\left(c_{2}^{1 C}\right)}
$$

which is (5.8). By (A.11), the inequalities $c_{1}^{0 C}<w^{0}$ and $c_{2}^{0 C}>w^{0}-d$ imply (5.7), hence $v^{\prime}\left(c_{1}^{1}\right)<v^{\prime}\left(c_{2}^{1}\right)$. By (A.16) therefore, $u^{\prime}\left(c_{1}^{0 C}\right)<u^{\prime}\left(c_{2}^{0 C}\right)$ and $c_{1}^{0 C}>c_{2}^{0 C}$, which completes the proof of (5.6). (5.5) follows by Lemma 2.1 .

Proof of Proposition 6.1. I first prove the second statement of the proposition. Suppose that $\left\{\left(\mathbf{q}^{W H^{k}},\left\{c_{1}^{h W H^{k}}, c_{2}^{h W H^{k}}\right\}_{h=0}^{H^{k}}, \eta^{W H^{k}}\right)\right\}$ is a sequence of Walrasian rational-expectations equilibria with $\lim _{k \rightarrow \infty} H^{k}=\infty$. By (5.2), the pairs $\left(c_{1}^{0 W H^{k}}, c_{2}^{0 W H^{k}}\right)$ all belong to the compact set $\left[w^{0}-d, w^{0}\right]^{2}$. By the equal-treatment property of the allocations, $\left(\left\{c_{1}^{h H^{k}}, c_{2}^{h H^{k}}\right\}_{h=0}^{H^{k}}, \eta^{H^{k}}\right)$ and feasibility, it follows that, for any $h, c_{1}^{h W H^{k}}=w^{1}+\frac{1}{H^{k}}\left(w^{0}-c_{1}^{0 W H^{k}}\right)$ and $c_{2}^{h W H^{k}}=w^{1}+\frac{1}{H^{k}}\left(w^{0}-d-c_{1}^{0 W H^{k}}\right)$ both converge to $w^{1}$ as $H^{k}$ goes out of bounds. Therefore $\lim _{k \rightarrow \infty} \frac{v^{\prime}\left(c_{1}^{1 W H^{k}}\right)}{v^{\prime}\left(c_{2}^{1 W H^{k}}\right)}=1$. By (5.4), it follows that $\lim _{k \rightarrow \infty} \frac{u^{\prime}\left(c_{1}^{0 W H^{k}}\right)}{u^{\prime}\left(c_{2}^{0 W H^{k}}\right)}=1$, and hence that $\lim _{k \rightarrow \infty} c_{1}^{0 W H^{k}}-\lim _{k \rightarrow \infty} c_{2}^{0 W H^{k}}=0$ and $\lim _{k \rightarrow \infty}\left(u\left(c_{1}^{0 W H^{k}}\right)-u\left(c_{2}^{0 W H^{k}}\right)\right)=0$. By Lemma 2.1 , it follows that $\lim _{k \rightarrow \infty} \eta^{H^{k}}=0$. Now (6.2) follows from the participants' first-order conditions and the fact that $q_{1}^{W H^{k}}+q_{2}^{W H^{k}}=1$ for all $k$. Given (6.2), the value (6.1) of the common limit of $c_{1}^{0 W H^{k}}$ and $c_{2}^{0 W H^{k}}$ follows from the budget constraint of household 0 . 
Turning to the first statement of the proposition, I note that for any sequence $\left\{\left(\mathbf{q}^{W H^{k}},\left\{c_{1}^{h W H^{k}}, c_{2}^{h W H^{k}}\right\}_{h=0}^{H^{k}}, \eta^{W H^{k}}\right)\right\}$ of Walrasian rational-expectations equilibria, condition (ii) in Definition 5.1 implies

$$
U\left(c_{1}^{0 W H^{k}}, c_{2}^{0 W H^{k}}, \eta^{W H^{k}}\right) \geq U\left(w^{0}, w^{0}-d, \eta\left(w^{0}, w^{0}-d\right)\right)
$$

for all $k$. If $\lim _{k \rightarrow \infty} H^{k}=\infty$, the argument just given implies that, as $k$ becomes large, the left-hand side of this inequality converges to $u\left(w^{0}-\right.$ $\left.p_{2}(0) d\right)$. Thus, if a Walrasian rational-expectations equilibrium exists for arbitrarily large $H$, it must be the case that

$$
u\left(w^{0}-p_{2}(0) d\right) \geq U\left(w^{0}, w^{0}-d, \eta\left(w^{0}, w^{0}-d\right)\right) .
$$

Since Lemma 2.1 implies $p_{2}\left(\eta\left(w^{0}, w^{0}-d\right)\right)<1$, it follows that

$$
u\left(w^{0}-p_{2}(0) d\right)>\left(1-p_{2}(0)\right) u\left(w^{0}\right)+p_{2}(0) u\left(w^{0}-d\right)
$$

and hence that $p_{2}(0)<1$. Conversely, if $p_{2}(0)$ is close to one, (A.17) is violated, and, for any sufficiently large $H$, a Walrasian rational-expectations equilibrium fails to exist.

The proof of Proposition 6.2 is divided into several steps. For transparency, two of these steps are stated as separate lemmas.

Lemma A.2 Under the maintained assumptions about the data of the model, for any $H$, a Cournot rational-expectations equilibrium exists.

Proof. For $\left(c_{1}^{0}, c_{2}^{0}\right) \in \bar{\Gamma}$, feasibility implies $c_{1}^{0} \leq w^{0}+H w^{1}$ and $c_{2}^{0} \leq$ $w^{0}-d+H w^{1}$, so $\bar{\Gamma}$ is bounded. Proposition 4.3 shows that $\bar{\Gamma}$ is also closed. Given the continuity of $U(., .,$.$) and \eta(.,$.$) , it follows that the maximization$ problem of household 0 has a solution, i.e., there exists a pair $\left(c_{1}^{0}, c_{2}^{0}\right)$ that maximizes $U\left(c_{1}^{0}, c_{2}^{0}, \eta\left(c_{1}^{0}, c_{2}^{0}\right)\right)$ on $\bar{\Gamma}$. By the definition of $\bar{\Gamma}$, the associated price vector $\mathbf{q}=\mathbf{q}^{*}\left(c_{1}^{0}, c_{2}^{0}\right)$ validates the market-clearing conditions (4.6) and (4.7). With $\left(c_{1}^{h}, c_{2}^{h}\right)=\left(C_{1}^{1}(\mathbf{q}), C_{2}^{1}(\mathbf{q})\right), h=1,2, \ldots, H$, the allocation $\left(\left\{c_{1}^{h}, c_{2}^{h}\right\}_{h=0}^{H}, \eta\right)$ is feasible; moreover, for any $h,\left(c_{1}^{h}, c_{2}^{h}\right)=\left(C_{1}^{1}(\mathbf{q}), C_{2}^{1}(\mathbf{q})\right)$ maximizes $V\left(c_{1}^{h}, c_{2}^{h}, \eta^{*}(\mathbf{q})\right)$ under the budget constraint given by $\mathbf{q}$. The price vector $\mathbf{q}$ and allocation $\left(\left\{c_{1}^{h}, c_{2}^{h}\right\}_{h=0}^{H}, \eta\right)$ thus satisfy all the conditions for a Cournot rational-expectations equilibrium. 
Lemma A.3 For $H=1,2, \ldots$, let $\hat{\Gamma}^{H}$ be the set of consumption plans $\left(c_{1}^{0}, c_{2}^{0}\right)$ satisfying $w^{0}-d \leq c_{2}^{0} \leq c_{1}^{0} \leq w^{0}$ as well as

$$
\begin{gathered}
\left(1-p_{2}\left(\eta\left(c_{1}^{0}, c_{2}^{0}\right)\right)\right) v^{\prime}\left(w^{1}+\frac{1}{H}\left(w^{0}-c_{1}^{0}\right)\right)\left(c_{1}^{0}-w^{0}\right) \\
+p_{2}\left(\eta\left(c_{1}^{0}, c_{2}^{0}\right)\right) v^{\prime}\left(w^{1}+\frac{1}{H}\left(w^{0}-d-c_{2}^{0}\right)\right)\left(c_{2}^{0}-\left(w^{0}-d\right)\right) \leq 0 .
\end{gathered}
$$

As $H$ goes out of bounds, the sets $\hat{\Gamma}^{H}$ converge in the Hausdorff topology to the set $\Phi^{*}$ of consumption plans $\left(c_{1}^{0}, c_{2}^{0}\right)$ satisfying $w^{0}-d \leq c_{2}^{0} \leq c_{1}^{0} \leq w^{0}$ as well as (6.4),

$$
\left(1-p_{2}\left(\eta\left(c_{1}^{0}, c_{2}^{0}\right)\right)\right) c_{1}^{0}+p_{2}\left(\eta\left(c_{1}^{0}, c_{2}^{0}\right)\right) c_{2}^{0} \leq w^{0}-p_{2}\left(\eta\left(c_{1}^{0}, c_{2}^{0}\right)\right) d .
$$

Proof. The proof follows the same lines as the corresponding argument in the proof of Proposition 3.2. For any $H, \hat{\Gamma}^{H}$ is a closed subset of the compact set $\left[0, w^{0}\right]^{2}$ and is itself compact. Any sequence $\left\{\left(c_{1}^{0 H}, c_{2}^{0 H}\right)\right\}_{H=1}^{\infty}$ of elements of $\hat{\Gamma}^{H}, H=1,2, \ldots$, must therefore have a convergent subsequence. Since $v($.$) is a concave function and, for any H,\left(c_{1}^{0 H}, c_{2}^{0 H}\right) \in \hat{\Gamma}^{H}$ satisfies $w^{0}-c_{1}^{0 H} \geq 0 \geq w^{0}-d-c_{2}^{0 H}$, the validity of (A.18) implies that $\left(c_{1}^{0 H}, c_{2}^{0 H}\right) \in$ $\hat{\Gamma}^{H}$ satisfies (6.4). Since $p_{2}($.$) and \eta(.,$.$) are continuous, it follows that$ any limit point $\left(c_{1}^{0}, c_{2}^{0}\right)$ of a sequence $\left\{\left(c_{1}^{0 H}, c_{2}^{0 H}\right)\right\}_{H=1}^{\infty}$ of elements of $\hat{\Gamma}^{H}$, $H=1,2, \ldots$, must satisfy $(6.4)$ as well. Trivially, such a limit point also satisfies $w^{0}-d=c_{2}^{0} \leq c_{1}^{0} \leq w^{0}$, and hence is an element of $\Phi^{*}$.

Conversely, I also show that for any point $\left(c_{1}^{0}, c_{2}^{0}\right) \in \Phi^{*}$ there exists a sequence $\left\{\left(c_{1}^{0 H}, c_{2}^{0 H}\right)\right\}_{H=1}^{\infty}$ of elements of $\hat{\Gamma}^{H}, H=1,2, \ldots$, that converges to $\left(c_{1}^{0}, c_{2}^{0}\right)$.

If $w^{0}-d=c_{2}^{0} \leq c_{1}^{0} \leq w^{0}$, then trivially the pair $\left(c_{1}^{0}, c_{2}^{0}\right)$ itself belongs to $\hat{\Gamma}^{H}$ for all $H$, and there is nothing left to prove.

Suppose therefore that $w^{0}-d<c_{2}^{0} \leq c_{1}^{0} \leq w^{0}$. Using precisely the same construction as in the proof of Lemma A.1, for any sufficiently large integer $n$, define $\left(c_{1}^{0 n}, c_{2}^{0 n}\right)$ so that $w^{0}-d<c_{2}^{0 n} \leq c_{1}^{0 n}=c_{1}^{0}-\frac{1}{n} \leq w^{0}, c_{2}^{0 n} \leq c_{2}^{0}$, and $\eta\left(c_{1}^{0 n}, c_{2}^{0 n}\right)=\eta\left(c_{1}^{0}, c_{2}^{0}\right)$. The argument following (A.3) in the proof of Lemma A.1 shows that for the given $n$, there exists $H^{n}$ such that any $H \geq H^{n}$, one has

$$
\begin{gathered}
\left(1-p_{2}(\eta)\right) v^{\prime}\left(w^{1}+\frac{1}{H}\left(w^{0}-c_{1}^{0 n}\right)\right) \frac{1}{H}\left(w^{0}-c_{1}^{0 n}\right) \\
+p_{2}(\eta) v^{\prime}\left(w^{1}+\frac{1}{H}\left(w^{0}-d-c_{2}^{0 n}\right)\right) \frac{1}{H}\left(w^{0}-d-c_{2}^{0 n}\right) \geq 0,
\end{gathered}
$$

and hence that $\left(c_{1}^{0 n}, c_{2}^{0 n}\right) \in \hat{\Gamma}^{H}$. Upon setting $\left(c_{1}^{0 H}, c_{2}^{0 H}\right)=\left(c_{1}^{0 n}, c_{2}^{0 n}\right)$ if $H^{n} \leq$ $H \leq H^{n+1}$, one obtains a sequence of elements of $\hat{\Gamma}^{H}, H=1,2, \ldots$ that converges to the given $\left(c_{1}^{0}, c_{2}^{0}\right) \in \Phi^{*}$. 
Proof of Proposition 6.2. For any $H$, the existence of a Cournot rational-expectations equilibrium $\left(\mathbf{q}^{C H},\left\{c_{1}^{h C H}, c_{2}^{h C H}\right\}_{h=0}^{H}, \eta^{C H}\right)$ is established in Lemma A.2. By the first-order conditions for households $1, \ldots, H$, equilibrium prices satisfy

$$
\frac{q_{1}^{C H}}{q_{2}^{C H}}=\frac{\left(1-p_{2}\left(\eta^{C H}\right)\right)}{p_{2}\left(\eta^{C H}\right)} \frac{v^{\prime}\left(w^{1}+\frac{1}{H}\left(w^{0}-c_{1}^{0 C H}\right)\right)}{v^{\prime}\left(w^{1}+\frac{1}{H}\left(w^{0}-d-c_{2}^{0 C H}\right)\right)} .
$$

As $H$ goes out of bounds, $\frac{1}{H}\left(w^{0}-c_{1}^{0 C H}\right)$ and $\frac{1}{H}\left(w^{0}-d-c_{2}^{0 C H}\right)$ both go to zero, and the ratio of marginal utilities on the right-hand side of (A.19) goes to one. Any limit point $\left(\mathbf{q}^{*}, \eta^{*}\right)$ of the sequence $\left\{\mathbf{q}^{C H}, \eta^{C H}\right\}$ must therefore satisfy (6.3).

I next claim that for any $H$ the pair $\left(c_{1}^{0 C H}, c_{2}^{0 C H}\right)$ maximizes (A.4), i.e., $U\left(c_{1}^{0}, c_{2}^{0}, \eta\left(c_{1}^{0}, c_{2}^{0}\right)\right)$ over the set $\hat{\Gamma}^{H}$ defined in Lemma A.3. By assumption, $\left(c_{1}^{\mathrm{OCH}}, c_{2}^{\mathrm{OCH}}\right)$ belongs to the set of pairs satisfying (4.11), and hence (A.18), for the given $H$. By Proposition 5.5, $\left(c_{1}^{0 C H}, c_{2}^{0 C H}\right)$ also satisfies (5.6). Therefore $\left(c_{1}^{0 C H}, c_{2}^{0 C H}\right)$ belongs to $\hat{\Gamma}^{H}$. By Proposition $4.3,\left(c_{1}^{0 C H}, c_{2}^{0 C H}\right)$ maximizes (A.4) under the constraint (4.11), so if $\left(c_{1}^{0 C H}, c_{2}^{0 C H}\right)$ does not maximize $(A .4)$ over $\hat{\Gamma}^{H}$, there must exist $\left(\hat{c}_{1}^{0}, \hat{c}_{2}^{0}\right)$ such that $U\left(\hat{c}_{1}^{0}, \hat{c}_{2}^{0}, \eta\left(\hat{c}_{1}^{0}, \hat{c}_{2}^{0}\right)\right)>$ $U\left(c_{1}^{0 H}, c_{2}^{0 H}, \eta\left(c_{1}^{0 H}, c_{2}^{0 H}\right)\right)$ and $\left(\hat{c}_{1}^{0}, \hat{c}_{2}^{0}\right)$ satisfies (A.18) with a strict inequality. But then, there exists a pair $\left(c_{1}^{0}, c_{2}^{0}\right)>>\left(\hat{c}_{1}^{0}, \hat{c}_{2}^{0}\right)$ such that (i) $u\left(c_{1}^{0}\right)-u\left(c_{2}^{0}\right)=$ $u\left(\hat{c}_{1}^{0}\right)-u\left(\hat{c}_{2}^{0}\right)$ and therefore, by Lemma $2.1, \eta\left(c_{1}^{0}, c_{2}^{0}\right)=\eta\left(\hat{c}_{1}^{0}, \hat{c}_{2}^{0}\right)$, and (ii) $\left(c_{1}^{0}, c_{2}^{0}\right)$ satisfies (A.18) as an equation and hence (4.11). By strict monotonicity then,

$$
U\left(c_{1}^{0}, c_{2}^{0}, \eta\left(c_{1}^{0}, c_{2}^{0}\right)\right)>U\left(\hat{c}_{1}^{0}, \hat{c}_{2}^{0}, \eta\left(\hat{c}_{1}^{0}, \hat{c}_{2}^{0}\right)\right)>U\left(c_{1}^{0 C H}, c_{2}^{0 C H}, \eta\left(c_{1}^{0 C H}, c_{2}^{0 C H}\right)\right),
$$

contrary to the assumption that $\left(c_{1}^{0 C H}, c_{2}^{0 C H}\right)$ maximizes $(A .4)$ subject to (4.11). The assumption that $\left(c_{1}^{0 C H}, c_{2}^{0 C H}\right)$ does not maximize $(A .4)$ over $\hat{\Gamma}^{H}$ thus leads to a contradiction and must be false.

By Lemma A.3, the sets $\hat{\Gamma}^{H}$ converge to the set $\Phi^{*}$ of pairs $\left(c_{1}^{0}, c_{2}^{0}\right)$ that satisfy $w^{0}-d \leq c_{2}^{0} \leq c_{1}^{0} \leq w^{0}$ as well as (6.4). By the maximum theorem (see, e.g., Hildenbrand [20], pp. 29f.), it follows that any limit point $\left(c_{1}^{0 *}, c_{2}^{0 *}, \eta^{*}\right)$ of the sequence $\left\{\left(c_{1}^{0 C H}, c_{2}^{0 C H}, \eta^{C H}\right)\right\}_{H=1}^{\infty}$ is a solution to the problem of maximizing (A.4) over the set $\Phi^{*}$. As discussed in the Proposition $3.2,\left(c_{1}^{0 *}, c_{2}^{0 *}, \eta^{*}\right)$ is then also a solution to the problem of maximizing (A.4) under the constraint (6.4).

Proof of Lemma 7.1. If the lemma is false, there exists a price system $\mathbf{q} \in \Sigma$ for which conditions $(7.9)-(7.11)$ have two solutions $\left\{\left(\hat{z}_{1}^{0 i}, \hat{z}_{2}^{0 i}\right)\right\}_{i=1}^{m}$ and $\left\{\left(\bar{z}_{1}^{0 i}, \bar{z}_{2}^{0 i}\right)\right\}_{i=1}^{m}$, with associated effort vectors $\hat{\boldsymbol{\eta}}=\boldsymbol{\eta}\left(\left\{\left(\hat{z}_{1}^{0 i}, \hat{z}_{2}^{0 i}\right)\right\}_{i=1}^{m}\right)$ and 
$\overline{\boldsymbol{\eta}}=\boldsymbol{\eta}\left(\left\{\left(\bar{z}_{1}^{0 i}, \bar{z}_{2}^{0 i}\right)\right\}_{i=1}^{m}\right)$. Distinctness of $\left\{\left(\hat{z}_{1}^{0 i}, \hat{z}_{2}^{0 i}\right)\right\}_{i=1}^{m}$ and $\left\{\left(\bar{z}_{1}^{0 i}, \bar{z}_{2}^{0 i}\right)\right\}_{i=1}^{m}$ in combination with the budget constraint (7.9) implies $\hat{\boldsymbol{\eta}} \neq \overline{\boldsymbol{\eta}}$, hence $\pi(\mathbf{e}, \hat{\boldsymbol{\eta}}) \neq$ $\pi(\mathbf{e}, \overline{\boldsymbol{\eta}})$ for at least one $\mathbf{e} \in E$. Let $\mathbf{e}^{*} \in E$ be the elementary event for which the ratio $\frac{\pi(\mathbf{e}, \hat{\boldsymbol{\eta}})}{\pi(\mathbf{e}, \overline{\boldsymbol{\eta}})}$ is highest. By (7.5), it must be the case that, for each $i$, one has $\frac{p_{s_{i}\left(\mathbf{e}^{*}\right)}\left(\eta\left(\hat{z}_{1}^{0 i}, \hat{z}_{2}^{0 i}\right)\right)}{p_{s_{i}\left(\mathbf{e}^{*}\right)}\left(\eta\left(\bar{z}_{1}^{0 i}, \bar{z}_{2}^{i 0}\right)\right)} \geq 1$, with strict inequality for some $i$. By Lemma 2.1, it follows that $\hat{z}_{s_{i}\left(\mathbf{e}^{*}\right)}^{0 i} \geq \bar{z}_{s_{i}\left(\mathbf{e}^{*}\right)}^{0 i}$ for all $i$, with strict inequality for some $i$. Hence,

$$
\sum_{i=1}^{m} \hat{z}_{s_{i}\left(\mathbf{e}^{*}\right)}^{0 i}>\sum_{i=1}^{m} \bar{z}_{s_{i}\left(\mathbf{e}^{*}\right)}^{0 i} .
$$

By (7.10), it follows that

$$
z\left(\mathbf{e}^{*} \mid \mathbf{q}, \hat{\boldsymbol{\eta}}\right)<z\left(\mathbf{e}^{*} \mid \mathbf{q}, \overline{\boldsymbol{\eta}}\right) .
$$

By the first-order conditions for the determination of $z(\mathbf{e} \mid \mathbf{q}, \boldsymbol{\eta})$, for any $\mathbf{e}, \mathbf{q}$, and $\boldsymbol{\eta}$, one also has

$$
\frac{\pi\left(\mathbf{e}^{*}, \hat{\boldsymbol{\eta}}\right) v^{\prime}\left(w^{1}+z\left(\mathbf{e}^{*} \mid \mathbf{q}, \hat{\boldsymbol{\eta}}\right)\right)}{\pi(\mathbf{e}, \hat{\boldsymbol{\eta}}) v^{\prime}\left(w^{1}+z(\mathbf{e} \mid \mathbf{q}, \hat{\boldsymbol{\eta}})\right)}=\frac{q\left(\mathbf{e}^{*}\right)}{q(\mathbf{e})}
$$

and

$$
\frac{\pi\left(\mathbf{e}^{*}, \overline{\boldsymbol{\eta}}\right) v^{\prime}\left(w^{1}+z\left(\mathbf{e}^{*} \mid \mathbf{q}, \overline{\boldsymbol{\eta}}\right)\right)}{\pi(\mathbf{e}, \overline{\boldsymbol{\eta}}) v^{\prime}\left(w^{1}+z(\mathbf{e} \mid \mathbf{q}, \overline{\boldsymbol{\eta}})\right)}=\frac{q\left(\mathbf{e}^{*}\right)}{q(\mathbf{e})}
$$

for all $\mathbf{e} \in E$, hence

$$
\frac{v^{\prime}\left(w^{1}+z\left(\mathbf{e}^{*} \mid \mathbf{q}, \hat{\boldsymbol{\eta}}\right)\right)}{v^{\prime}\left(w^{1}+z\left(\mathbf{e}^{*} \mid \mathbf{q}, \overline{\boldsymbol{\eta}}\right)\right)}=\frac{\pi\left(\mathbf{e}^{*}, \overline{\boldsymbol{\eta}}\right)}{\pi\left(\mathbf{e}^{*}, \hat{\boldsymbol{\eta}}\right)} \frac{\pi(\mathbf{e}, \hat{\boldsymbol{\eta}})}{\pi(\mathbf{e}, \overline{\boldsymbol{\eta}})} \frac{v^{\prime}\left(w^{1}+z(\mathbf{e} \mid \mathbf{q}, \hat{\boldsymbol{\eta}})\right)}{v^{\prime}\left(w^{1}+z(\mathbf{e} \mid \mathbf{q}, \overline{\boldsymbol{\eta}})\right)}
$$

for all $\mathbf{e} \in E$. By the definition of $\mathbf{e}^{*}$, it follows that

$$
\frac{v^{\prime}\left(w^{1}+z\left(\mathbf{e}^{*} \mid \mathbf{q}, \hat{\boldsymbol{\eta}}\right)\right)}{v^{\prime}\left(w^{1}+z\left(\mathbf{e}^{*} \mid \mathbf{q}, \overline{\boldsymbol{\eta}}\right)\right)}<\frac{v^{\prime}\left(w^{1}+z(\mathbf{e} \mid \mathbf{q}, \hat{\boldsymbol{\eta}})\right)}{v^{\prime}\left(w^{1}+z(\mathbf{e} \mid \mathbf{q}, \overline{\boldsymbol{\eta}})\right)} .
$$

Since $z\left(\mathbf{e}^{*} \mid \mathbf{q}, \hat{\boldsymbol{\eta}}\right)<z\left(\mathbf{e}^{*} \mid \mathbf{q}, \overline{\boldsymbol{\eta}}\right)$, this in turn implies

$$
1<\frac{v^{\prime}\left(w^{1}+z(\mathbf{e} \mid \mathbf{q}, \hat{\boldsymbol{\eta}})\right)}{v^{\prime}\left(w^{1}+z(\mathbf{e} \mid \mathbf{q}, \overline{\boldsymbol{\eta}})\right)}
$$

hence $z(\mathbf{e} \mid \mathbf{q}, \hat{\boldsymbol{\eta}})<z(\mathbf{e} \mid \mathbf{q}, \overline{\boldsymbol{\eta}})$ for all $\mathbf{e} \in E$. But then

$$
\sum_{\mathbf{e} \in E} q(\mathbf{e}) z(\mathbf{e} \mid \mathbf{q}, \hat{\boldsymbol{\eta}})<\sum_{\mathbf{e} \in E} q(\mathbf{e}) z(\mathbf{e} \mid \mathbf{q}, \overline{\boldsymbol{\eta}})=0,
$$


which is incompatible with the assumption that the net-trade plan $\{z(\mathbf{e} \mid \mathbf{q}, \hat{\boldsymbol{\eta}})\}_{\mathbf{e} \in E}$ maximizes (7.7) subject to (7.8). The assumption that the lemma is false thus leads to a contradiction.

The proofs of Lemma 7.2, Proposition 7.3, and Proposition 7.5 are straightforward extensions of the proofs of Lemma 4.2, Proposition 4.3, and Proposition 6.2 and are left to the reader.

Proof of Proposition 7.6. Fix $H$. For any $m$ and any pair $\left(x_{1}, x_{2}\right) \in$ $[-d, 0] \times[0, d]$, consider the problem of maximizing $U\left(w^{0}+z_{1}^{0}, w_{2}^{0}-d+z_{2}^{0}, \eta\right)$ under the constraint

$$
\begin{array}{r}
p_{1}\left(\eta\left(w^{0}+z_{1}^{0}, w_{2}^{0}-d+z_{2}^{0}\right)\right) \varphi\left(z_{1}^{0 i},\left(x_{1}, x_{2}\right)^{m-1}, \boldsymbol{\eta}_{-i}\right) z_{1}^{0 i} \\
+p_{2}\left(\eta\left(w^{0}+z_{1}^{0}, w_{2}^{0}-d+z_{2}^{0}\right)\right) \varphi\left(z_{2}^{0 i},\left(x_{1}, x_{2}\right)^{m-1}, \boldsymbol{\eta}_{-i}\right) z_{2}^{0 i}=0,
\end{array}
$$

where $\left(x_{1}, x_{2}\right)^{m-1}$ is the $m-1$-fold replication of $\left(x_{1}, x_{2}\right)$ and $\boldsymbol{\eta}_{-i}$ is the $m-1$-fold replication of $\eta\left(w^{0}+x_{1}, w_{2}^{0}-d+x_{2}\right)$. Let $\zeta^{m}\left(x_{1}, x_{2}\right)$ be the set of solutions to this maximization problem, and note that $\left\{z_{1}^{0 C}, z_{2}^{0 C}, \eta^{C}\right\}_{i=1}^{m}$, with price system $\mathbf{q}^{C}$ given by Lemma 7.2, is a symmetric Cournot rationalexpectations equilibrium for the economy with $m$ insurance buyers and $m H$ insurers if and only if $\left(z_{1}^{0 C}, z_{2}^{0 C}, \eta^{C}\right) \in \zeta^{m}\left(z_{1}^{0 C}, z_{2}^{0 C}\right)$. The proposition is thus equivalent to the assertion that for any sufficiently large $m$, the projection of $\zeta^{m}$ to the space of net-trade plans has a fixed point.

Let $\left(z_{1}^{0 *}, z_{2}^{0 *}, \eta^{*}\right)$ be the unique solution to the problem of maximizing $U\left(w^{0}+z_{1}^{0}, w_{2}^{0}-d+z_{2}^{0}, \eta\right)$ under the constraint (7.20). By an argument similar to the one used in the proof of Proposition 6.2, for any sequences $\left\{\left(x_{1}^{m}, x_{2}^{m}\right)\right\}_{m=1}^{\infty}$ and $\left\{\left(z_{1}^{0 m}, z_{2}^{0 m}, \eta^{m}\right)\right\}_{m=1}^{\infty}$ such that $\left(x_{1}^{m}, x_{2}^{m}\right) \in$ $[-d, 0] \times[0, d]$ and $\left(z_{1}^{0 m}, z_{2}^{0 m}, \eta^{m}\right) \in \zeta^{m}\left(x_{1}^{m}, x_{2}^{m}\right)$ for all $m$, the maximum theorem implies $\lim _{m \rightarrow \infty}\left(z_{1}^{0 m}, z_{2}^{0 m}, \eta^{m}\right)=\left(z_{1}^{0 *}, z_{2}^{0 *}, \eta^{*}\right)$, i.e. the best-response correspondences $\zeta^{m}$ converge uniformly to the constant function with value $\left(z_{1}^{0 *}, z_{2}^{0 *}, \eta^{*}\right)$.

I claim that for any sufficiently large $m, \zeta^{m}$ must actually be singlevalued, i.e. the best-response correspondence is actually a function. Existence of a fixed point - and hence of a Cournot rational-expectations equilibrium - then follows from the observation that for any $m$, by the maximum theorem, the correspondence $\zeta^{m}$ is upper hemi-continuous.

To prove that for any sufficiently large $m, \zeta^{m}$ must actually be singlevalued, suppose the contrary. Then there exist sequences $\left\{\left(x_{1}^{m^{\prime}}, x_{2}^{m^{\prime}}\right)\right\},\left\{\left(z_{1}^{0 m^{\prime}}, z_{2}^{0 m^{\prime}}, \eta^{m^{\prime}}\right)\right\}$, and $\left\{\left(\hat{z}_{1}^{0 m^{\prime}}, \hat{z}_{2}^{0 m^{\prime}}, \hat{\eta}^{m^{\prime}}\right)\right\}$ such that, for any $m^{\prime},\left(x_{1}^{m^{\prime}}, x_{2}^{m^{\prime}}\right) \in[-d, 0] \times[0, d]$, $\left(z_{1}^{0 m^{\prime}}, z_{2}^{0 m^{\prime}}, \eta^{m^{\prime}}\right) \in \zeta^{m^{\prime}}\left(x_{1}^{m^{\prime}}, x_{2}^{m^{\prime}}\right),\left(\hat{z}_{1}^{0 m^{\prime}}, \hat{z}_{2}^{0 m^{\prime}}, \hat{\eta}^{m^{\prime}}\right) \in \zeta^{m^{\prime}}\left(x_{1}^{m^{\prime}}, x_{2}^{m^{\prime}}\right)$, and moreover $\left\{\left(z_{1}^{0 m^{\prime}}, z_{2}^{0 m^{\prime}}, \eta^{m^{\prime}}\right)\right\}$, and $\left\{\left(\hat{z}_{1}^{0 m^{\prime}}, \hat{z}_{2}^{0 m^{\prime}}, \hat{\eta}^{m^{\prime}}\right)\right\}$ are distinct. Because, for any 
$m^{\prime}$, both, $\left(z_{1}^{0 m^{\prime}}, z_{2}^{0 m^{\prime}}, \eta^{m^{\prime}}\right)$ and $\left(\hat{z}_{1}^{0 m^{\prime}}, \hat{z}_{2}^{0 m^{\prime}}, \hat{\eta}^{m^{\prime}}\right)$ maximize $U\left(w^{0}+z_{1}^{0}, w_{2}^{0}-\right.$ $\left.d+z_{2}^{0}, \eta\right)$ on the constraint set, there must also be a triple $\left(\bar{z}_{1}^{0 m^{\prime}}, \bar{z}_{2}^{0 m^{\prime}}, \bar{\eta}^{m^{\prime}}\right)$, between $\left(z_{1}^{0 m^{\prime}}, z_{2}^{0 m^{\prime}}, \eta^{m^{\prime}}\right)$ and $\left(\hat{z}_{1}^{0 m^{\prime}}, \hat{z}_{2}^{0 m^{\prime}}, \hat{\eta}^{m^{\prime}}\right)$, which generates a local minimum of $U\left(w^{0}+z_{1}^{0}, w_{2}^{0}-d+z_{2}^{0}, \eta\right)$ on the constraint set.

As mentioned above, the maximum theorem implies that both $\left(\hat{z}_{1}^{0 m^{\prime}}, \hat{z}_{2}^{0 m^{\prime}}, \hat{\eta}^{m^{\prime}}\right)$ and $\left(\hat{z}_{1}^{0 m^{\prime}}, \hat{z}_{2}^{0 m^{\prime}}, \hat{\eta}^{m^{\prime}}\right)$ converge to $\left(z_{1}^{0 *}, z_{2}^{0 *}, \eta^{*}\right)$ as $m^{\prime}$ becomes large. Therefore the sequence $\left\{\left(\bar{z}_{1}^{0 m^{\prime}}, \bar{z}_{2}^{0 m^{\prime}}, \bar{\eta}^{m^{\prime}}\right)\right\}$ of local minimizers of $U\left(w^{0}+z_{1}^{0}, w_{2}^{0}-\right.$ $\left.d+z_{2}^{0}, \eta\right)$ subject to $\left(\right.$ A.20) must also converge to $\left(z_{1}^{0 *}, z_{2}^{0 *}, \eta^{*}\right)$ as $m^{\prime}$ becomes large. But then, at $\left(z_{1}^{0 *}, z_{2}^{0 *}, \eta^{*}\right)$, the second-order conditions for maximization of $U\left(w^{0}+z_{1}^{0}, w_{2}^{0}-d+z_{2}^{0}, \eta\right)$ under the constraint (7.20) cannot hold with strict inequality, contrary to the assumptions made. The assumption that $\zeta^{m}$ fails to be single-valued if $m$ is sufficiently large thus leads to a contradiction and must be false.

\section{References}

[1] A. Admati, P. Pfleiderer, and J. Zechner, Large Shareholder Activism, Risk Sharing, and Financial Market Equilibrium, J. Polit. Economy 102 (1994), 1097 - 1130.

[2] R. Arnott and J.E. Stiglitz, The Basic Analytics of Moral Hazard, Scand. J. Economics 90 (1988), 383 - 413.

[3] K.J. Arrow and R.C. Lind, Uncertainty and the Evaluation of Public Investments, Amer. Econ. Rev. 60 (1970), 364 -378.

[4] A. Bennardo and P.A. Chiappori, Bertrand and Walras Equilibria Under Moral Hazard, J. Polit. Economy 111 (2003), 785 - 817.

[5] A. Bisin and P. Gottardi, Competitive Equilibria with Asymmetric Information, J. Econ. Theory 87 (1999), 1-48.

[6] A. Bisin and P. Gottardi, Competitive Equilibria with Asymmetric Information: Existence with Entry Fees, Rev. Econ. Dynam. 6 (2003), $313-338$.

[7] A. Bisin and D. Guaitoli, Moral Hazard and Non-Exclusive Contracts, RAND J. Econ. 35 (2004).

[8] K. Borch, Equilibrium in a Reinsurance Market, Econometrica 30 (1962), 424 - 444. 
[9] A. Cournot, "Recherches sur les principes mathématiques de la théorie des richesses," Paris, 1838.

[10] D. Gale and M.F. Hellwig, Informed Speculation in Large Markets, Discussion Paper, University of Pittsburgh, 1987.

[11] D. Gale and M.F. Hellwig, Competitive Insurance Markets with Asymmetric Information: A Cournot-Arrow-Debreu Approach, Discussion Paper No. 02-19, Sonderforschungsbereich 504, Universität Mannheim, 2002.

[12] S.J. Grossman, The Existence of Futures Markets, Noisy Rational Expectations and Informational Externalities, Rev. Econ. Stud. 44 (1977), $431-449$.

[13] S.J. Grossman, An Introduction to the Theory of Rational Expectations under Asymmetric Information, Rev. Econ. Stud. 48 (1981), 541 - 560.

[14] O.D. Hart, Monopolistic Competition in a Large Economy with Differentiated Commodities, Rev. Econ. Stud. 46 (1979), 1 - 30.

[15] O.D. Hart, Imperfect Competition in General Equilibrium: An Overview of Recent Work, in "Frontiers of Economics" (K.J. Arrow and S. Honkapohja, Eds.), pp. 100 - 149, Blackwell, Oxford, 1985.

[16] M.F. Hellwig, Moral Hazard and Monopolistically Competitive Insurance Markets, Geneva Pap. Risk Ins. 8 (1983), 44 - 71.

[17] M.F. Hellwig, Moral Hazard and Non-Price Equilibria in Competitive Insurance Markets, Discussion Paper No. 109, Sonderforschungsbereich 21, University of Bonn, 1983

[18] M.F. Hellwig, Nonlinear Incentive Contracting in Walrasian Markets: A Cournot Approach, Discussion Paper No. 09-42, Sonderforschungsbereich 504, Universität Mannheim, 2000.

[19] E. Helpman and J.J. Laffont, On Moral Hazard in General Equilibrium, J. Econ. Theory 10 (1975), 8 - 23.

[20] W. Hildenbrand, "Core and Equilibria of a Large Economy," Princeton University Press, Princeton, N.J., 1974.

[21] G. Jaynes, Equilibria in Monopolistically Competitive Insurance Markets, J. Econ. Theory 19 (1978), 394 - 422. 
[22] N.R. Kocherlakota, The Effects of Moral Hazard on Asset Prices When Financial Markets are Complete, J. Monet. Econ. 41 (1998), 39 - 56.

[23] A.S. Kyle, Informed Speculation with Imperfect Competition, Rev. Econ. Stud. 56 (1989), 317 - 355.

[24] M.B. Lisboa, Moral hazard and general equilibrium in large economies, Econ. Theory 18 (2001), 555-575

[25] L. Makowski, A Characterization of Perfect Competition with Production, J. Econ. Theory 22 (1980) 208 - 222.

[26] L. Makowski, Perfect Competition, the Profit Criterion, and the Organization of Economic Activity, J. Econ. Theory 22 (1980), 222 - 241.

[27] E. Malinvaud, The Allocation of Individual Risks in Large Markets, J. Econ. Theory 4 (1972), 312 - 328.

[28] J. Marshall, Moral Hazard, Amer. Econ. Rev. 66 (1976), 880 - 890.

[29] W. Novshek, and H. Sonnenschein, Cournot and Walras Equilibrium, J. Econ. Theory 19 (1978), 223-266.

[30] J. Ostroy, The No-Surplus Condition as a Characterization of Perfectly Competitive Equilibrium, J. Econ. Theory 22 (1980), 183 - 207.

[31] M. Pauly, Overinsurance and the Public Provision of Insurance, Quart. J. Econ. 88 (1974), 44 - 54.

[32] E. Prescott, and R.M. Townsend, Pareto Optima and Competitive Equilibria with Adverse Selection, Econometrica 52 (1984), 21-45.

[33] J. Roberts and H. Sonnenschein, On the Foundations of the Theory of Monopolistic Competition, Econometrica 45 (1977), 101 - 113.

[34] K. Roberts, The Limit Points of Monopolistic Competition, J. Econ. Theory 22 (1980), 256 - 278.

[35] M. Rothschild and J.E. Stiglitz, Equilibrium in Competitive Insurance Markets, Quart. J. Econ. 90 (1976), 629 - 649.

[36] L. Shapley and M. Shubik, Trade Using One Commodity as a Means of Payment, J. Polit. Economy 85 (1977), 937-968.

[37] S. Shavell, On Moral Hazard and Insurance, Quart. J. Econ. 93 (1979), $541-562$. 
[38] J.E. Stiglitz, Risk, Incentives, and Insurance: The Pure Theory of Moral Hazard, Geneva Pap. Risk Ins. 8 (1983), 4 - 33.

[39] Symposium on Non-Cooperative Approaches to the Theory of Perfect Competition, J. Econ. Theory 22 (1980). 